\title{
Complexity Begets Crosscutting, Dooms Hierarchy (Another Paper on Natural Kinds)*
}

\author{
by Joyce C. Havstad \\ Oakland University (Department of Philosophy), Rochester (Michigan), USA \\ Email: jhavstad@oakland.edu \\ ORCID iD: 0000-0003-1923-7860
}

\begin{abstract}
There is a perennial philosophical dream of a certain natural order for the natural kinds. The name of this dream is 'the hierarchy requirement' (or 'assumption' or 'thesis'). According to this postulate, proper natural kinds form a taxonomy which is both unique (i.e., there is only one taxonomy of such natural kinds) and traditional (i.e., said taxonomy consists of nested relations between specific and then more general kinds, each kind occupying one and only one particular place within that framework of relations). Here I demonstrate that complex scientific objects exist: objects which generate different systems of scientific classification, produce myriad legitimate alternatives amongst the nonetheless still natural kinds, and make the hierarchical dream impossible to realize, except at absurdly great cost. Philosophical hopes for a certain order in nature cannot be fulfilled. Natural kinds crosscut one another, ubiquitously so, and this crosscutting spells the end of the hierarchical dream.
\end{abstract}

Keywords: classification; complexity; hierarchy; natural kinds; natural order; scientific essentialism

*This is a pre-print dated January 8, 2020. The paper is forthcoming in Synthese. 
The so-called 'natural kinds' are living a double life in philosophy today. In certain companypredominately amongst philosophers of science—natural kinds just are whichever empirical categories scientists effectively deploy to understand and manipulate the world. Because scientists in one discipline often have different experimental and explanatory interests from scientists in another, scientists in different disciplines often have different systems of categorization. These different systems are generally suited to the aims and practices of the sciences in which they are deployed, and these systems will often classify in crisscrossing or crosscutting ways, ${ }^{1}$ yet each still tracks select scientific facts about whatever is being categorized. Here is an elegant exemplar of this sort of view:

Kind-talk simply reflects distributions of causal properties. One describes cases in which distributions are sociable enough to be useful, convenient, or interesting as instances of kinds. But no classification, so long as it is made on the basis of properties in the world, whether in terms of an essence or a cluster, is more or less objective than any other. The subjectivity of the choice, generally made to serve everyday or scientific ends, is thus independent of the question of what is natural. (Chakravartty 2007, 178-179)

To philosophers of science of this sort, ${ }^{2}$ natural kinds are more than merely nominal— they have empirical elements, after all, and they are epistemically effective-but they fall far short of the divine. It makes little sense to talk of these natural kinds in hushed tones. There is no one true taxonomy here; no solitary way of carving nature "where the joint is."3 Rather, there are many acceptable cuts to make, and thereby, many acceptable kinds to form. Sometimes, we will be able to

\footnotetext{
${ }^{1}$ My use of this terminology is due to, and nicely explained by: Khalidi (1993, 1998); Tobin (2010).

${ }^{2}$ There are many. Here is one representative quote from each of the past four decades: "[D]ifferent sorts of classification schemes are indexed to different scientific purposes" (Bursten 2018, 18); "Those in the grip of Plato's metaphor suppose not only that there is a privileged way to divide nature into objects but that there are natural ways to assort those objects into kinds... I see a dependence on human capacities and human purposes" (Kitcher 2001, 48); "All the kinds of which we are aware occur in the social setting of those interested" (Hacking 1990, 116); and "When the classificatory problem is approached from a more restricted point of view, that is, with an interest only in a certain range of properties, many peaks will disappear, while others may be emphasized... Even within biology different interests call for the emphasis of different distinctions" (Dupré 1981, 83).

${ }^{3}$ As expressed by Socrates in Plato's Phaedrus (265e). A related notion is articulated by the Stranger to Young Socrates in Plato's Statesman (287c).
} 
relate such kinds from one branch of science to kinds from another, and in an orderly fashion; but in many cases, we will not.

Other philosophers have an alternative —an elevated—view of natural kinds. Amongst the more metaphysically-inclined, natural kinds are often more than just those empirical categories which scientists effectively deploy in order to understand and manipulate the world. Even if it is the case that scientists in one discipline have different interests from scientists in another, and respectively different systems of categorization, there could still be a subset of scientific kinds - the natural ones, properly understood — for which there are no acceptable alternatives from any perspective. On this sort of view, admitting a group into the ranks of the natural kinds requires more than just identifying an objective division in some bit of the world; it requires identifying the singularly best way of objectively dividing that bit of the world. Consider the following programmatic declaration:

If the world has no intrinsic structure, I thought, then, in principle, any single way of conceptualizing the world might be as good as any other. There would be an objective world, and perhaps from a human perspective, a best description of it. But such a description might not also be best from the point of view of an alien being, whose epistemic values might well be different from ours. However, if the world had a natural kind structure, I reasoned, then we should be able to classify things in the world objectively in two quite different ways vertically, in terms of the distinct objects that are the members of the natural kinds, and horizontally - in terms of the kinds to which they belong, and hence the properties they must have by virtue of their memberships of these kinds. In that case, there would be a set of objective facts about the world - facts that would exist independently of how we, or any other being, might think or reason about the world. The hypothesis of natural-kind structure of reality thus promised to yield a solution to the objective knowledge problem, for objective knowledge could then be defined with reference to this structure. (Ellis 2001, xiii)

To metaphysicians of this inclination, ${ }^{4}$ natural kinds are incredibly special kinds. They are based on

\footnotetext{
${ }^{4}$ Again, there are many. Here are representative quotes from three founders of this tradition: "An important class, philosophically as well as linguistically, is the class of general names associated with natural kinds — that is, with classes of things that we regard as of explanatory importance; classes whose normal distinguishing characteristics are 'held together' or even explained by deep-lying mechanisms" (Putnam 1970, 187; italics original); "Therefore I claim, again, that a satisfactory account of natural kinds must fulfill our two conditions: members of natural kinds have real essences, and natural kinds characteristically lend themselves to scientific investigation" (Wilkerson 1988, 34); and 'I will call proper natural kinds of this sort 'eternal natural kinds', later distinguishing
} 
intrinsic rather than extrinsic properties; they track essential as opposed to accidental features of their members; they explain the necessary character of certain observed regularities in the world (those we tend to christen laws of nature); they license our best scientific inferences; and they solve the objective knowledge problem. Natural kinds, of this sort, are the rarest birds among us. To the most fervent of such believers, natural kind knowledge is the product of incredible scientific effort and ingenuity, and the discovery of natural kinds is what the very best science aims to achieve.

The ultimate aim of this paper is to demonstrate that even if we restrict our account of natural kinds in this latter way (reserving the term for our most select scientific groupings), we should not expect a single, hierarchical arrangement of the natural kinds (a solitary taxonomy of our most fundamental groupings) to follow. This failure, I will argue, is due to the scientific existence of complexity. Complexity begets crosscutting, which dooms hierarchy.

The argument happens in a series of parts. In section one, I characterize what is variously termed the hierarchy assumption/requirement/thesis. In section two, I propose that we distinguish three classificatory activities: characterization, individuation, and organization. This step is a crucial one, as it prevents discussion of the subsequent case study from being dismissed on normative grounds — as a mere description of how science is actually, but not ideally, practiced. Then I introduce the case study itself. In section three, I characterize a set of complex scientific kinds known as nuclear receptors. In section four, I describe a trio of equally legitimate, intradisciplinaryyet-nonetheless-crosscutting systems for arranging the nuclear receptors. In section five, I deploy an analysis of complexity in order to explain the documented classificatory divergence. In section six, I

them from 'historical natural kinds'. The various branches of physics and of chemistry concern eternal natural kinds exclusively, assuming that we take such disciplines as historical geography and cosmogony to be applications rather than branches of physics and chemistry. Astronomy, in so far as it deals with the various kinds of bodies in outer space (astrophysics) rather than with the placement and interactions among specific historical bodies, concerns eternal kinds. We can call these sciences 'eternal sciences"' (Millikan 1999, 50). 
assess the implications of my case study for "one true taxonomy" visions of natural kindhood. In section seven, I block a potential appeal to the epistemic success of science as a way of dismissing my case. Finally, in section eight, I relate my discussion of hierarchy, crosscutting, and complexity to notions of sameness, similarity, and simplicity—notions which tend to play important, though oft overlooked, roles in philosophical debate about natural kinds.

\section{The Expectation of Hierarchy}

There are different ways to express the expectation that natural kinds, properly understood, should permit of only one arrangement - that strict natural kindhood entails an exclusive set of structured relationships among the natural kinds. Robert A. Wilson calls this idea 'the ordering assumption', and glosses it as "there is one way in which different natural kinds are related to one another" (Wilson 1999, 189; italics original). Here is Brian Ellis in 2001, articulating Richmond Thomason's view from 1969, of what Ellis terms 'the hierarchy requirement': 'if anything is a member of more than one natural kind, then one of these kinds must be a species of the other" (Ellis 2001, 56). P. D. Magnus explains and historicizes the situation thusly:

A tradition going back to Aristotle insists that each individual belongs to just one maximally specific kind. There is another more generic kind that includes everything of the specific kind as well as others. That kind is included entirely in an even more generic kind. Natural kinds are nested in one another like stacking dolls. Call this the bierarchy assumption. (Magnus 2012, 37; italics original)

And in an article that should have buried the notion for good, but somehow did not, Muhammad Ali Khalidi explains what he calls 'the hierarchic thesis' as the idea "that natural categories cannot crosscut one another" (Khalidi 1998, 35). To "crosscut" is just the term which Khalidi prefers to use for kinds that overlap, neither perfectly nor with total subsumption. ${ }^{5}$

\footnotetext{
${ }^{5}$ Examination of the literature reveals that introduction of the term 'crosscutting kinds' is often de re attributed to Dupré (1993) — by Dupré himself (2006), for instance, and by other scholars such as Tobin (2010) and Potochnik (2011, 2017). Dupré comes close to introducing the term itself: he uses
} 
According to Khalidi, there are two reasons why the claim about hierarchy is important for the strict view of natural kinds: (1) "this claim is tied to the further claim that there is one best classification scheme in each area of human inquiry" (Khalidi 1998, 35), and (2) the claim "seems to be needed in arguing that each such category has a unique essence associated with it across possible worlds" (Khalidi 1998, 35). So, Khalidi endeavors to see if the hierarchy requirement can be met. First, he surveys kind terms from ordinary language ('red' and 'round'), and quickly establishes that such categories are often crosscutting. The hierarchical claim obviously fails in that domain. Next, he considers some scientific candidates (such as 'parasite' and 'poison'), and again, Khalidi quickly establishes that these categories are often crosscutting. Perhaps these are not the real scientific kinds, though? Khalidi immediately furnishes many examples of putatively real scientific categories which nonetheless crosscut one another ('larva', 'pupa', and 'imago' cut across species categories; 'solid', 'liquid', and 'gas' cut across categories of the Periodic Table). Then, Khalidi posits that different, crosscutting systems of categorization likely emerge from different interests. He writes:"[i]f classification is always relative to certain interests, we would expect some taxonomies to reorganize some of the same entities in different ways without displacing existing ones" (Khalidi 1998, 42). Eventually, Khalidi suggests that we can and ought to use this notion of interests-in conjunction with that of subject matter-in order to demarcate domains of scientific inquiry. He claims that "it is not enough to point to a set of entities or phenomena in order to specify the focus

the antonym 'clear-cut' to describe the opposite kind of kinds in his "Natural Kinds and Biological Taxa" (1981, 73); shortly thereafter he describes some classifications as "blurred" (1983, 334); and a decade later, in his "The Disorder of Things," Dupré writes of ways of classifying which "crossclassify" one another (1993, 18 and 36). However, if we are being quite strict about the introduction of 'crosscutting kinds', then I think de dicto attribution goes to Khalidi-for his use of 'crisscrossing categories' in "Carving Nature at the Joints" $(1993,108)$ and the titular 'crosscutting categories' in his "Natural Kinds and Crosscutting Categories" (1998). In the latter case, Khalidi (1998) appears to have been inspired by Wimsatt's talk of levels, entities, and perspectives which do or do not "crosscut" (1994, 262-265). 
or area of inquiry of a particular discipline or subdiscipline" (Khalidi 1998, 47). In sum, Khalidi

characterizes different scientific domains as at least partially demarcated by different scientific

interests — interests which conspire to generate different and crosscutting but still legitimate

classification systems, both among and within different domains. He concludes that:

At first, it might seem that different disciplines investigate different spatiotemporal levels, whereas different subdisciplines investigate the same levels relative to different interests. But there are many exceptions to this rule. Some disciplines cut through a wide range of levels, as in the case of physics. Within some subdisciplines, different interests may generate more than one classification scheme. In toxicology itself, poisons may be classified in terms of the target organ they affect, in terms of the chemical mechanism they exploit, in terms of their poisoning potential, in terms of their route of absorption into the body, and so on. (Khalidi 1998, 49-50)

Khalidi correspondingly rejects the hierarchic thesis, arguing that "uniqueness is not a promising construal of what makes a system of categories 'natural"' (Khalidi 1998, 50).

I think that Khalidi is right about all of this-especially, about the proposed disassociation of natural categories from unique ones. And yet it is clear from the literature that the idea of one true natural kind taxonomy still holds sway. Even some who style themselves anti-realist about natural kinds find this notion alluring:

According to the Categorical Bottleneck. Account the natural kinds correspond to those categories that are metaphorical 'bottlenecks' in the following sense: they reflect the categories that both ourselves and a large array of scientific inquirers with epistemic aims and cognitive capacities different from our own would sanction in common, thereby converging on a single set of categories and kinds from multiple, distinct starting positions or points-of-view. (Franklin-Hall 2015, 940; italics original)

In this representative recent case, Laura Franklin-Hall proposes an account that is in part justified by its commitment to interest-dependent but not interest-relative natural kinds. I suspect that the unabashed interest-relativity of Khalidi's account of supposedly real scientific kinds goes a long way towards explaining its failure to wake more philosophers from their ongoing hierarchical dream.

If you start with a kind like 'poison'-with its very general meaning, broad swath of application, and obvious human investment - then it will not be difficult to find different ways of arranging the items within the kind (in this case, individual poisons) with respect to one another. 
Each of these arrangements will likely seem as legitimate as the others do, and as the category itself does. But I think that proponents of the elevated view of natural kinds are likely to regard this starting point — the category 'poison' — as not all that legitimate, as a candidate natural kind, in the first place. In such circumstances, the fact that the category admits of equally legitimate but different arrangements of the sub-kinds within it is likely to provide further reason to reject 'poison' as a proper natural kind, rather than to reject the hierarchy requirement. So let us consider a crosscutting case that should be much harder for the strict natural kind theorist to reject.

\section{Characterization, Individuation, and Organization}

Before we can do that, the introduction of some clarificatory terminology is required. Cases of interdisciplinary divergence in classification are common and should be familiar: these are cases in which theorists from different domains (internal or external to science) use different classification systems for what they are calling or viewing as the same ideas, objects, processes, events, or phenomena of interest. To provide just one notable example, John Dupré (1981, 1993) discusses various classificatory practices pertaining to a particular botanical family (Liliaceae). Although botanists might be happy grouping various decorative flowers along with onion and garlic, others (such as chefs or gardeners) will likely prefer alternative arrangements. Hence, we have divergent classification systems for the same set of plants: different systems for tracking the different interests which different domains have.

In contrast, when Khalidi (1998) discusses toxicologists arranging different poisons differently with respect to one another, on the basis of different factors_affected organ, chemical mechanism, poison potential, and means of absorption-Khalidi is providing an example of intradisciplinary classificatory divergence. Cases like these are ones in which theorists from within the same domain nonetheless use different classification systems for what they are calling or viewing as 
the same ideas, objects, processes, events, or phenomena of interest. Biological species should be a familiar case here. When Dupré (1981, 1993, 2001), Khalidi (1993, 1998), and many others discuss problems with the species category—-such as how difficult it is for evolutionary biologists to settle on the meaning of the term 'species', or for bacteriologists to specify the relationships between their species taxa— these philosophers of science are discussing intradisciplinary classificatory divergence.

But the demarcation between intra- and interdisciplinary classificatory divergence is not the only pertinent distinction to draw. ${ }^{6}$ In discussing problems with the species category just now, I mentioned both a difficulty defining 'species' and a difficulty arranging already-identified species with respect to one another. And there is an implicit third difficulty that can arise-an intermediate one-lurking between these two already-made-explicit classificatory difficulties: that of species identification. This sort of difficulty can occur even with a definition of the term in hand, and without having to arrange identified species with respect to one another. In short, there are three distinct classificatory activities being referred to here; and this sort of classificatory diversity is not limited to the species case. Whenever we classify, there are elements of characterization, individuation, and organization to consider. Classificatory characterization focuses the meaning or definition of the categories (or kind terms) that we are considering. Classificatory individuation focuses on identifying which items in the world (often known as tokens) belong in the categories (or kinds, or types) that we are considering. Classificatory organization focuses on arranging the various categories (or kinds, or types) that we are considering with respect to one another. ${ }^{7}$ In philosophical

\footnotetext{
${ }^{6}$ Please see Tobin (2010) for a related (but not the same) distinction between 'intertaxonomic' and 'intrataxonomic' crosscutting; see also Beebee (2013) for the addition of 'artificial' and 'interparadigm' crosscutting.

${ }^{7}$ Imagine we are engaged in a project of classifying frozen desserts. Efforts at characterization might include claims like "gelato is made with little or no eggs, while ice cream typically includes eggs." Efforts at individuation might include claims like "the contents of that container - the one currently in your freezer, labeled 'artisanal gelato', and which you bought at your Midwestern US grocery store last week-consist of ice cream, not gelato." Efforts at organization might include claims like "ice
} 
parlance, the focus of classificatory characterization is intension (and perhaps connotation); the focus of classificatory individuation is extension (and perhaps denotation); and the focus of classificatory organization is taxonomy (and perhaps relations like that of genus and species, though in an inclusive, metaphysical-not-necessarily-biological sense). Consider the following illustration:

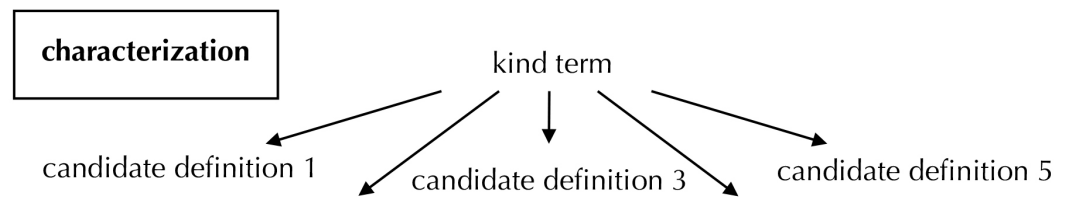

candidate definition $2 \quad$ candidate definition 4
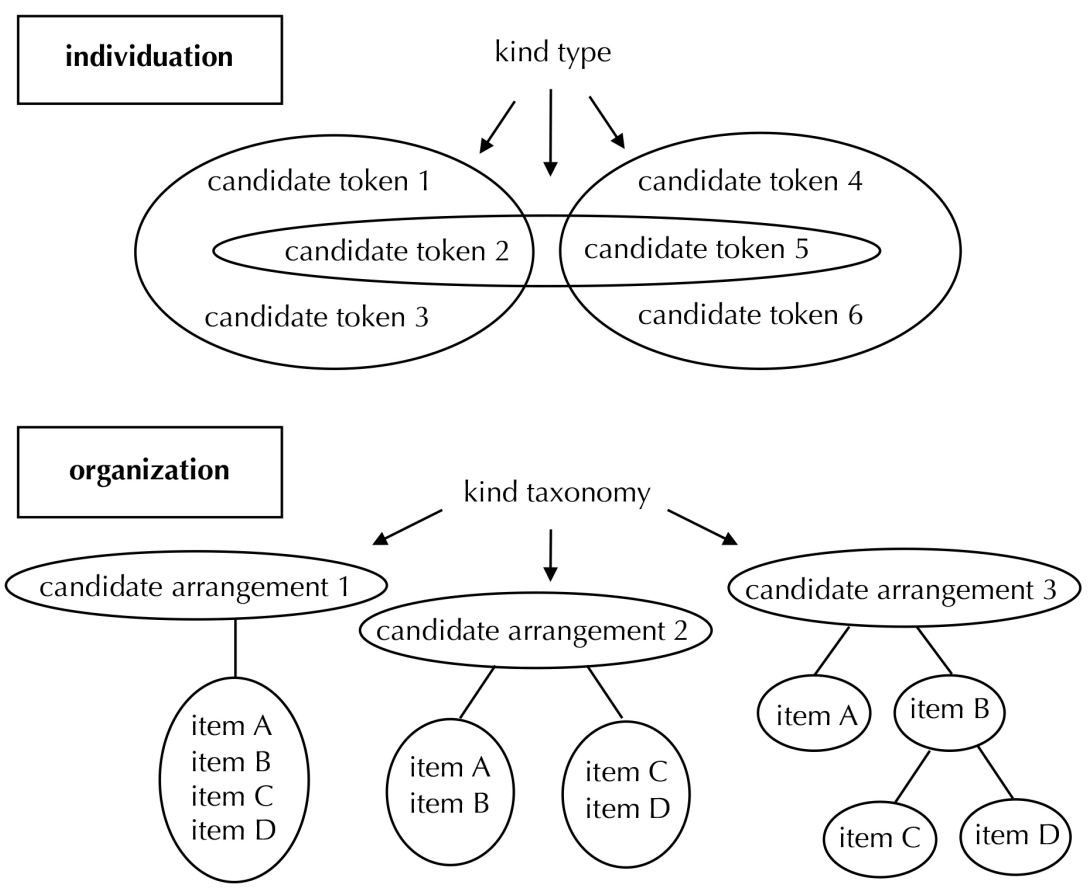

Fig. 1 Three classificatory activities, each with a visual depiction of the sort of choices being offered by that activity. To put it crassly, characterization is about building boxes, individuation is about putting things in boxes, and organization is about arranging boxes.

As the figure shows, characterization, individuation, and organization are all quite distinct classificatory activities. To summarize the proposed distinction in theoretical terms: characterization

cream and gelato are more closely related to one another than either is to sorbet." 
tends to focus on definition; individuation on instances; and organization on taxonomy. They each inform each other, of course, and comprehensive classification efforts consider all three elements together-rather than focusing on just one element, to the exclusion of the others. But it is worth conceptually disentangling these elements of classification, especially when dealing with difficult cases.

To demonstrate the proposed distinction in action, and with a difficult case, let us reconsider the species problem. Many biologists and philosophers of biology have considered the question of how to define the term 'species', and given divergent answers. ${ }^{8}$ This is primarily a question about the classificatory characterization of species. There is a reproductive characterization of the species concept, according to which species are defined in terms of factors like interbreeding (e.g., Mayr 1957); an ecological characterization, according to which species are defined in terms of factors like niche (e.g., Van Valen 1976); a phylogenetic characterization, according to which species are defined in terms of factors like historical connectedness of individuating characteristics (e.g., Cracraft 1983); a cohesion characterization, according to which species are defined in terms of factors like demographic and genetic integration (e.g., Templeton 1989); and more. Some theorists have even given pluralist answers to the 'species' question—answers that defend divergent "conceptions" of the species “concept” as not just acceptable but appropriate (e.g., Ereshefsky 1992).?

Although the question of how to define the term 'species' emphasizes characterization, how that question is answered also interacts with issues of classificatory individuation. Utilizing a biological conception of species — with its emphasis on interbreeding capabilities — might make each asexual

\footnotetext{
${ }^{8}$ For an alternative demonstration of the distinction between classificatory characterization, individuation, and organization (involving the term 'protein' rather than 'species'), please see Havstad (2016).

${ }^{9}$ Here I am relying on the concept-conception distinction credited to Hart (1961), employed by Rawls (1971), and introduced to me by Burge (1993) and Hardimon (2003).
} 
organism its own species. Alternatively, utilizing a cohesion conception of species might group a lineage of certain asexual organisms together. Candidate tokens will be differentially typed according to different species concepts; alternative conceptions of the species concept can generate alternative instances of species individuation. ${ }^{10}$ The direction of influence can also go the other way: firm commitments to particular instances of species individuation can also affect which among the many species conceptions seem plausible.

Finally, to point to elements of classificatory organization, it is possible to arrange individuated species differentially with respect to one another-producing distinct taxonomies of the relations among species. Some argue, for instance, that bird species originate within the group of dinosaurs known as maniraptoran theropods (e.g., Smith et al. 2015); others dispute this, arguing that bird species are descended from a group of basal archosaurs (e.g., Feduccia 2013). At least until such disagreement is resolved, there are divergent taxonomies depicting the evolutionary relationships amongst various bird, dinosaur, and early reptile species.

Divergence, disagreement, and controversy run rampantly through all three of the distinct dimensions of species classification: in disputes over definitions of the term (characterization), in confusion around the individuation of particular organisms and (meta)populations as belonging to one or more species (individuation), and in construction of alternative phylogenies (organization). This makes the species problem a very hard problem to solve, and I suspect it also tempts many strict natural kind theorists to simply walk away from the species table. Although it surely would have been nice for such theorists if species had turned out to be natural kinds, properly understood, perhaps the nature of evolution and the messiness of biology are determined to thwart this desire.

\footnotetext{
${ }^{10}$ Note that alternative conceptions of a concept do not have to generate alternative systems of individuation. It is possible for competing definitions of a term to have the same extension. So, characterization-level pluralism does not necessarily produce individuation-level pluralism.
} 
Even spanning (somewhat) different interpretations of what constitutes traditional or strict natural kinds, properly understood, the dominant conclusion of those who attend to the metaphysicallyfocused literature is that species cannot meet such requirements (e.g., Wilson 1982; Wilkerson 1993; Ellis 2001, 2002; Wikforss 2005; though see Dumsday 2012 and Bird 2018). Those who admit species into the ranks of the natural kinds tend to come from the other side of the divide in the literature — the practice-emphasizing philosophy of science side — and to have a rather permissive or deflationary account of what a natural kind is (e.g., Boyd 1999; Griffiths 1999; Rieppel 2007; Brigandt 2009; Magnus 2012; Ereshefsky \& Reydon 2015; Khalidi 2018; though see Devitt 2008 and Elder 2008). These are not the sleepers who dream of natural kinds as nested stacking dolls.

Since I aim to a present a crosscutting case that is hard for the strict natural kind theorist to reject-leading them to abandon the hierarchy thesis instead-I will not be relying on biological species to make my argument. But the reaction of strict natural kind theorists to the species problem—with its entangled divergence in all three classificatory activities — does indicate what sort of case might (not) be worth pursuing. Despite the fact that philosophers of all stripes have long attended to questions of classificatory characterization — to understanding the meaning of category terms, and providing compelling definitions of those terms-the term 'species' has stubbornly resisted characterization, and this has led to its widespread abandonment as a candidate natural kind, properly understood. Hence, an uncharacterizable natural kind term is not a good candidate for my argument: its uncharacterizability threatens its prior plausibility as a natural kind. Such terms also permit unsatisfying deferrals of the issue at hand-conditional responses like "if there were a unified account of the species concept as a natural kind, properly understood, then there would be a unified way to structure the relationships among species taxa."

Cases involving problematic individuation, though similarly philosophically familiar, are also unsuited to my argument, though for different reasons. While vagueness is interesting, and the 
existence of tokens which confound classification by type is undisputable, philosophers have developed popular tools for dealing with this sort of classificatory divergence. Probably the dominant account of biological kindhood today is that of Boyd's $(1991,1999)$ homeostatic property cluster (HPC) kinds - and this view has accommodation for this sort of vagueness built right in. An entity that displays some but not all of the properties which usually characterize a member of an HPC kind may or may not be classified as a token of that type, and it is up to the natural kind theorist to decide whether natural kinds, properly understood, can accommodate such clusters. Divergent individuation within a natural kind is obviously and directly salient to questions about essence, but our primary subject matter is hierarchy. Hierarchy is most clearly implicated when it comes to classificatory organization, with its focus on taxonomy. A case of genuinely divergent classificatory organization among natural kinds just is a case where there is more than one true taxonomy of those purportedly natural kinds.

We have finally arrived back at Khalidi's intriguing case of divergent taxonomies of poisons among toxicologists (from Khalidi 1998, 49-50), and now we can articulate precisely what about the case utilizes crosscutting kindhood to threaten the hierarchic thesis: it is a case of intradisciplinary, divergent classificatory organization. The presentation of divergent classificatory organization (despite uncontroversial characterization and individuation) is crucial to successfully challenging the expectation of hierarchy. Plus, the intradisciplinary nature of the exposed classificatory divergence makes it difficult to dismiss the divergence as a mere byproduct of the dilution of epistemic interests by non-epistemic ones (as typically occurs when comparing taxonomies constructed by botanists, florists, gardeners, and chefs_-for instance). The intradisciplinary nature of Khalidi's case was not quite sufficient, however: the general category or subsuming kind ('poison') was not quite scientifically respectable enough. What my argument needs is a case of intradisciplinary, divergent classificatory organization-but for which the general category or subsuming kind is irrefutably 
scientific, rather than borrowed in any relevant way from natural language.

\section{Nuclear Receptors}

Allow me to introduce one such irrefutably scientific category: a group of genetic transcription factors commonly known as 'the nuclear hormone receptor superfamily'. This superfamily is a set of proteins which act as transcriptional activation switches-by working inside the nucleus of cells and binding directly to DNA, in order to change broad patterns of transcriptional activity. So, these are proteins which influence and control the production of other proteins. Nuclear receptors are both large and complex, and their transcriptional activation powers are triggered by either interaction with one another or with other molecules. Each term in the name-the (i) nuclear (ii) hormone (iii) receptor (iv) superfamily_communicates something about the characterization of the group. The group is (i) nuclear because its members act within the nucleus of cells, binding directly to DNA; the group consists of (ii) hormone (iii) receptors because its members are receptive to certain hormones, and because receiving such hormones causes the receptors to act on transcriptional processes; and the group is a (iv) superfamily because it contains significantly disparate sub-groups, or families. As I will show, the same scientists in the same labs within the same domain classify the nuclear receptors in a variety of ways, and use these various classification systems interactively and even simultaneously.

Before further detailing the divergent, intradisciplinary classificatory organization of the nuclear hormone receptor superfamily, however, I will first establish 'nuclear receptor' as a legitimate scientific kind-providing a brief history of the elucidation of the superfamily and answering any pertinent questions about its classificatory characterization and individuation along the way. Let us start with the smallest, earliest component of our story: the hormones themselves. In 1915, an American scientist named Edwin C. Kendall (1886-1972) initially reported using x-ray 
crystallography to solve the structure of thyroid hormone (Kendall 1915). However, Kendall's

proposed structure turned out to be incorrect, and the correct structure of thyroid hormone was not solved for another decade, by the Welsh chemist Sir Charles Robert Harrington (1897-1972). ${ }^{11}$ Thyroxine was first synthesized a year later (Harrington \& Barger 1927). Yet thyroid hormone is a molecule composed of only a few dozen atoms. The thyroid hormone receptors have primary sequences that are hundreds of amino acids long, and molecular weights of over 50,000 Dameaning, these molecules are composed of thousands of atoms. Compared to the hormones themselves, these are huge, unbelievably complicated molecules. They, and others like them, could not even begin to be understood until their encoding sequences were identified, and they could not be manufactured until scientists found out how to trick bacteria into making the receptors for them. The discovery of restriction enzymes in the 1960s, the advent of recombinant DNA technology in the 1970s, the decades-long development of sequencing methods, and the application of polymerase chain reaction (PCR) starting in the 1980s all contributed to open up the field of nuclear receptor research. ${ }^{12}$ Once cloning had allowed scientists to finally generate sufficient amounts of the molecules of interest, other techniques like PCR and sequencing could be applied to crack the complexity of their molecular codes.

One might wonder what makes the hormones and their receptors so intriguing, however. Thomas Hunt Morgan had argued as early as 1926 that, since all the cells of an organism contain the

\footnotetext{
${ }^{11}$ Various explanations for this mistake have been offered: for example, that Kendall was rushing at the end of 1914 in order to be able to present his findings at a meeting in early 1915; that he was unskilled at x-ray crystallography because he was a physiologist and not a chemist; and that he failed to appropriately isolate the hormone from the gland material in the first place. Do not fret about Kendall, however: he redeemed himself with his work on the hormones of the adrenal gland, for which (in 1950) he eventually received a Nobel Prize.

${ }^{12}$ These developments are well chronicled elsewhere, so I will not present them in any detail here. For more, please see Wright (1986), Rabinow (1996), Yi (2008), García-Sancho (2010), and Loenen et al. (2014)—among others.
} 
same genetic material, but different cell types develop and function very differently, there must be some kind of system of differential expression of select genes in different cell types (Morgan 1926, 1934). Morgan called the question of what this system could be a "paradox," or "the problem of development."13 The puzzle, for Morgan, was in figuring out how such a system might workwhether the answer was programmatic, successive action of genes; or a protoplasm-based kind of context-responsivity; or something else that had not yet been conceived. During his 1934 Nobel Lecture, Morgan glossed the way his contemporaries thought about developmental genetics as "all the genes acting in the same way all the time." Rush to work on Morgan's puzzle did not immediately overtake the field. Still, early efforts to deduce a resolution coalesced in the field of variable gene activity, and current efforts tend to reside in the fields of gene expression and evolutionary developmental biology. ${ }^{14}$ It is in the field of gene expression, as work related to solving Morgan's puzzle, that efforts to understand the nuclear mechanism of steroid hormone action eventually found a home.

Earl W. Sutherland, Jr. (a biochemist from Kansas, 1915-1974) is generally credited with doing the scientific work that categorically established how hormones work. Based on his research on cyclic 3, 5-AMP, Sutherland proposed a model of hormone signaling in which a hormone binds to the outer surface of an embedded trans-membrane receptor molecule, releasing another signaling molecule, previously bound to the inner surface of the trans-membrane receptor, into the cytoplasm (Sutherland \& Robinson 1966). His theoretical account was named the "second messenger hypothesis" because it includes a hormone (the first, extracellular messenger), as well as another

\footnotetext{
${ }^{13}$ From Morgan's Nobel Lecture, “The Relation of Genetics to Physiology and Medicine," given on June 4, 1934.

${ }^{14}$ For foundational work in the field of variable gene activity, see Stedman and Stedman (1950). For a nice review of the development of the field of gene expression, see Raj and van Oudenaarden (2008). For a brief assessment of evo-devo, see Arthur (2002).
} 
signaling molecule (the second, intracellular messenger), communicatively linked together via a transmembrane receptor (embedded in the boundary of the cell). This model is still used to characterize the signaling action of various hormones, and in 1971 Sutherland was awarded a Nobel Prize "for his discoveries concerning the mechanism of the action of hormones."15 But even as Sutherland gave his Nobel lecture, the honoree already had to add a caveat:

Of course the various relations in the endocrine system cannot all be understood in terms of a simple concept... the primary action of the steroid hormones appears to follow an entirely different pattern. (Sutherland 1972, 405) ${ }^{16}$

This rather understated qualification had to be made because of the unexpected results of Elwood V. Jensen's studies of the estrogen receptor. Estrogen is one of the steroid hormones.

It has been reported (by Moore 2012) that Jensen (1920-2012, born in North Dakota) began his work on the estrogen receptor as early as 1958 - perhaps before Sutherland had even begun to think of the second messenger hypothesis. The molecule Sutherland used (cyclic 3, 5-AMP) was only discovered in 1957. Jensen's experiments tagging and tracking estrogen with radioactive labels showed the hormone accumulating in the nucleus of cells, rather than bound to the surface of cells or even in the cytoplasm where most cellular interactions occur (Jensen \& Jacobson 1962). But these results confounded the theoretical expectations of the time, and other scientists lacked the means required to make sense of them. Sutherland's grudging admission of unresolved questions surrounding the mechanism of steroid hormone action-more than a decade after Jensen's initial results, and as Sutherland himself was accepting a Nobel prize for purportedly definitive work-is a fitting indicator of the field's stilted but eventual recognition of the import of Jensen's discovery.

\footnotetext{
${ }^{15}$ This description is from the Karolinska Institutet's October 1971 Press Release announcing their decision to award that year's Nobel Prize in Physiology or Medicine to Sutherland.

${ }^{16}$ This quote is from a published version of Sutherland's Nobel Lecture. It came out the year after the speech was given.
} 
In sum, the development of key techniques-moving from virology and bacteriology into molecular biology much more generally—encouraged a renewal of interest in Morgan’s puzzle, by providing both the methods for producing enough material for study and the means for dealing with the size and complexity of such material. ${ }^{17}$ After a long incubation period, the search for something that could differentially control gene expression rapidly became hurried and fierce. This something was dubbed a 'transcription factor'. Jensen's work on estrogen—work showing the hormone accumulating inside the nucleus, interacting directly with genetic material—made the estrogen receptor and other steroid hormone receptors extremely promising candidates as potential transcription factors. Altogether these conditions led to the (delayed) acceptance of Jensen's work, as well as to the capacity to actually figure out what his results indicated, and suddenly steroid hormone receptor research was transformed into an incredibly competitive and potentially lucrative scientific endeavor. Whoever could identify the protein-coding genetic sequence of a steroid hormone receptor could get credit both for that and for the discovery of a transcription factor.

This realization is followed by an explosion of scientific results. The first hormone to be cloned was human growth hormone (Martial et al. 1979), and just a handful of years later the genes encoding two different steroid hormone receptors_-glucocorticoid (Hollenberg et al. 1985) and estrogen (Walter et al. 1985)—had been sequenced and cloned as well. Following studies detected a surprising alignment of sequences from the $\operatorname{erb}-A$ protooncogene family with those of the alreadysequenced steroid hormone receptors — again, glucocorticoid (Evans et al. 1986) and estrogen (Green et al. 1986). By the end of year, it had been determined that what had been known as the c$\operatorname{erb}-A$ gene sequence actually encoded the receptor for thyroid hormone (Weinberger et al. 1986).

${ }^{17}$ This might be an opportune time to remind the reader that, in contrast with the case Khalidi (1998) used to demonstrate crosscutting ('poison'), this case has been chosen for its bona fide scientific chops. It is those chops which are currently being demonstrated, so that the case cannot be summarily dismissed as not scientific enough. 
But thyroid hormone is not a steroid. All steroids are derivatives of cholesterol, and thyroid hormone is a tyrosine-based hormone. So, alignment of the sequences for all three of these receptors — glucocorticoid, estrogen, and thyroid — suggested that physiological use of a signaling mechanism in which the receptor invaded the nucleus might not be restricted to steroid hormone receptors, those which Jensen had initially detected. It might include other hormone receptors, such as the one for thyroid, as well. The general term for any signaling molecule capable of activating a receptor is 'ligand'. So, alignment of the sequences of the glucocorticoid, estrogen, and thyroid receptors extended the group of known ligands for these receptors from just steroid hormones to also include thyroid hormone. To complicate matters even further, additional sequences were soon aligned; these sequences were shown to encode novel receptors; and the ligands identified for these receptors were vitamin D (McDonnell et al. 1987) and retinoic acid (Petkovich et al. 1987), the derivative of retinol or vitamin A. This discovery — that some vitamins and their derivatives might function, hormone-like, as signaling molecules_-was another startling revelation. One way of describing the evolving situation within this field, during the rapid developments of the late 1980s, is as one of surprising confrontation with a spreading pool of potential ligands for an ever-expanding group of receptors.

Early on in this process there was uncertainty about what to call the group of molecules being discovered. In the presentation abstract of one of the initial talks on the subject of a potential “family of eukaryotic transcriptional regulatory factors" (Evans et al. 1986, 63), the terms 'paradigm', 'class', 'mechanism', and 'family' were all used. The term 'superfamily' was first used publicly in the title of another talk later that year (Weinberger et al. 1986). That did not settle the matter, however. Early in 1988, another discussion claimed that "the isolation of novel steroid hormone receptor cDNAs is a step towards identifying a new hormone response system" (Giguère et al. 1988, 94). In this discussion, the terms 'class', 'group', and 'system' were used. But only a few months later, what 
turned out to be the definitive review was published, and the term 'superfamily' became firmly established (Evans 1988).

\section{Divergent Organization of the Superfamily}

Throughout the subsequent decade after Evans' review, ${ }^{18}$ additional cloning and alignment studies as well as the development of various screening techniques (such as low stringency hybridization screening) soon uncovered novel receptors, some with undetermined ligands (Mangelsdorf et al. 1995). Today there are 48 commonly recognized members of the nuclear hormone receptor superfamily in humans. There is one additional found in mice for a total of 49 in that species, and one missing in rats for a total of 47 there. Among less related species the numbers fluctuate quite a bit more: there are 21 nuclear receptors found in Drosophila melanogaster, for example, but more than 270 in Caenorhabditis elegans (Zhang et al. 2004). Nuclear receptors have been found in all but only the animals, and no evolutionary precursors have yet been found.

Among the 48 nuclear receptors found in humans, a handful are still missing the ligand, or receptor activation component, of their ligand-receptor-gene triad. In a somewhat unsettling extension of the family metaphor, these nuclear receptors are called 'orphan' receptors. Most of the receptors (orphans and the rest) have several names, since each lab that works with them tends to pick a name and attempt to get it established in the literature. Attempts have been made to standardize the nomenclature for individual receptors (Nuclear Receptors Nomenclature Committee 1999), but such attempts have only partially succeeded. There have also been many, many proposals for how to organize the nuclear receptors with respect to one another-but unlike the different

\footnotetext{
${ }^{18}$ According to Web of Science, Evans' (1988) review in Science has been cited 6,822 times. According to the same database, Watson and Crick's (1953) Nature paper on the structure of DNA has been cited 7,090 times. This is just to indicate, via an illustrative comparison, the significance of the scientific work on the nuclear hormone receptor superfamily. Data obtained 9:25pm EST, September 9, 2019.
} 
names for individual receptors, these distinct organization schemes are not gratuitous competitors; they are indispensable alternatives. The field does not seek to establish one exclusive, exhaustive system for organizing the nuclear receptors (as it does for naming them).

Just to be clear, what we have here is strong scientific consensus about what the nuclear receptors are (i.e., how to characterize them), as well as how many there are (i.e., how to individuate them). When you bundle species-specific nuclear receptors together, you get a superfamily of the nuclear receptors that exist within that species_-an encompassing kind composed of tightly related, narrower kinds. The lingering classificatory question is how to structure the relationships among the nuclear receptors (what we might call the sub-kinds relative to this question) within the superfamily (what we might call the super-kind relative to this question). And the nuclear receptors cluster with respect to one another in multiple, divergent ways. It is finally time to demonstrate what an irrefutably scientific case of intradisciplinary classificatory divergent organization looks like.

One set of schemes for organizing the nuclear receptors with respect to one another-the first set of such schemes to develop-is a group of procedural typologies of the nuclear hormone receptor superfamily united by a tendency to sort the nuclear receptors on the basis of mechanistic considerations such as kind of ligand, ${ }^{19}$ which tends to correlate with patterns of activation and binding, ${ }^{20}$ as well as with locational considerations such as where a nuclear receptor usually resides prior to activation. ${ }^{21}$ Initial typologies of the procedural sort simply divided the nuclear receptors into two groups: the endocrine receptors (ones for which steroid, thyroid, and other hormone-like molecules act as ligands) and the orphan receptors (ones for which ligands had not yet been

${ }^{19}$ A 'part' à la Glennan (2002), as well as Bechtel and Abrahamsen (2005); an 'entity' à la Craver and Darden (2013).

20 'Interactions' for Glennan (2002); 'operations' for Bechtel and Abrahamsen (2005); 'activities' for Craver and Darden (2013).

21 'Organization' for Bechtel and Abrahamsen (2005); 'set up conditions' for Craver and Darden (2013). 
identified). But the early discovery (Mangelsdorf et al. 1990) of a distinction between some of the nuclear receptors (those which function with copies of themselves, as homodimers) and others (those which require a co-factor for high-affinity binding, making them heterodimers) quickly led to more fine-grained procedural typologies. Consider the following pair of diagrams:

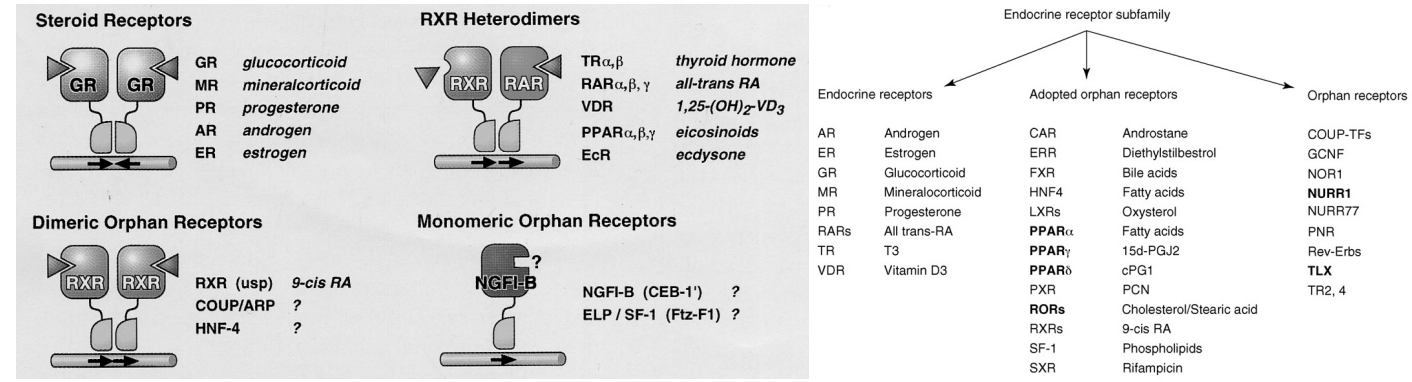

Fig. 2 On the left, an early division of the nuclear hormone receptor superfamily divided into four classes - the (homodimeric) steroid receptors, RXR heterodimers, dimeric orphan receptors, and monomeric orphan receptors (Mangelsdorf et al. 1995, 836). On the right, an updated version of the older style of typing the superfamily, simply separating nuclear receptors into three groups-the endocrine receptors, adopted orphans, and the (not yet adopted) orphans (Shi 2007, 441).

Both of these examples are based on procedural considerations, such as what kind of molecule activates each receptor, and whether the activation process requires an accessory molecule (a cofactor) or not. There have been many such typologies offered; these are just two instances.

But there are also many examples of an entirely different way of organizing the nuclear receptors with respect to one another. I have already discussed the importance of gene sequence alignment studies in unexpectedly expanding the nuclear hormone receptor superfamily to include members of unanticipated kinds (such as not just steroid but also other hormone receptors, and then not just hormone but also vitamins and other hormone-like receptors). With the advent of cheaper and easier sequencing techniques—plus ever-increasing computational power for aligning the sequenced material—came the development of phylogenetic methods for organizing the nuclear hormone receptor superfamily. These phylogenetic methods often rely on the concept of protein 'domain'. Protein domains are distinct, somewhat independent regions of these macromolecules 
(for a philosophical discussion of this concept, please see Love [2009]).

Nuclear receptors have five domains: an initial n-terminal domain (highly variable); a DNAbinding domain (highly conserved); a hinge region (between the previous domain and the next one); a ligand-binding domain (moderately conserved); and a final c-terminal domain (highly variable). Innovation in sequencing and computing technology means that amino acid sequence alignments, partial gene sequence alignments, domain-based alignments, and whole-sequence alignments can all be conducted. Expansion of the superfamily also makes it possible to vary the set of nuclear receptors being aligned, to include just those found in humans, or those found in humans, mice, and rats; or those found in humans and fruit flies; etc. Consider another pair of diagrams:
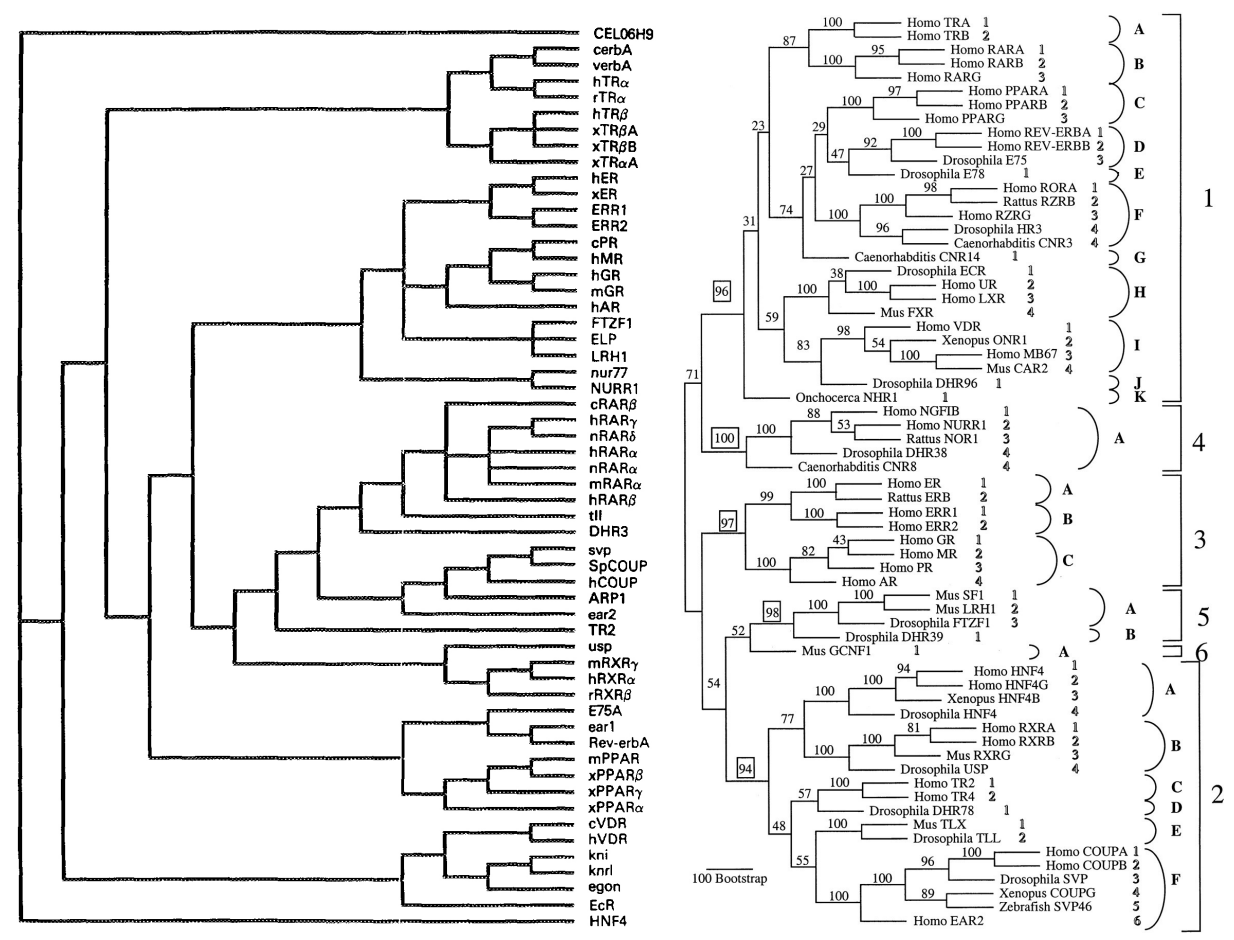

Fig. 3 On the left, an early phylogeny based on just the DNA binding domain of a set of nuclear receptors found in human, mouse, newt, rat, and frog species (DeteraWadleigh \& Fanning 1994, 198). On the right, another early phylogeny of the nuclear hormone receptor superfamily-one based on comparison of the DNAbinding domains, hinge regions, and ligand-binding domains of 65 nuclear receptors in vertebrates, arthropods, and nematodes (Nuclear Receptors Nomenclature Committee 1999, 161; based on work published in Laudet 1997). 
By varying which nuclear receptors are included as well as which domains are used for comparison, it is possible to generate myriad phylogenies of the nuclear hormone receptor superfamily. Regardless, certain phylogenetic "families" within the superfamily have become somewhat firmly established: the thyroid hormone receptor-like family, the retinoid X receptor-like family, the estrogen receptor-like family, the nerve growth factor IB-like family, the steroidogenic factor-like family, and the germ cell nuclear factor-like family. Within each of these families are further groupings into subfamilies; within each subfamily there are usually between one and four receptors.

Note that more recent phylogenies than the two depicted here can also incorporate some of the mechanistic (componential) information typically used to generate procedural typologies of the superfamily. For instance, the phylogeny depicted in Gronemeyer, Gustafsson, and Laudet (2004; supplementary information S1) indicates that blue-backgrounded receptors have steroidal ligands; the peach background indicates retinoids; yellow is for thyroid hormones; green is for fatty acids and derivatives; and the rest of the receptors were orphans at the time this particular phylogeny was generated. ${ }^{22}$ This is an example of a classificatory instance using phylogenetic information for its organizing principle, while communicating certain typological information as well. This sort of integrative classificatory practice will be further discussed in section six.

These two methods for generating various nuclear receptor classification systems- the procedurally typological and the phylogenetic — are responsible for most of the many distinct instances of nuclear hormone receptor superfamily organization (and these systems do classify the nuclear receptors in divergent ways). There is one additional, distinct method for organizing the nuclear hormone receptor superfamily, however. This method is typological, like the earliest

\footnotetext{
${ }^{22}$ Apologies for not reproducing this (or any other more recent) phylogeny. Printing a color figure is expensive; utilizing a color or otherwise figure from any of the Nature-affiliated journals is prohibitively so.
} 
classification systems, rather than phylogenetic - but it is designed to organize the nuclear receptors based on what they do rather than how they do it. There is, as yet, only one exemplar of this sort of effect-based rather than procedural typology of the nuclear hormone receptor superfamily:



Fig. 4 The "ring of physiology" (Bookout et al. 2006, 796).

This way of organizing the superfamily uses differential patterns of expression of genes coding for human and mouse nuclear receptors in distinct cell types, in order to group the receptors by various physiological associations. It represents a somewhat recent development in the organization of nuclear receptors. The late development of this method for organizing the superfamily is unsurprising given the massive technological effort that is required to track the expression of such large genes for 49 complex receptors throughout 39 different cell types. Such an approach became possible only once quantitative PCR was developed and certain advances in robotic, computing, and cloud technologies occurred. But now the requisite methods and tools are available — at least, they are available to incredibly well-funded, well-equipped laboratories.

The point of this third and final style of classification is to group the nuclear receptors by cellular expression, and associated cellular processes, in order to relate the nuclear receptors to 
clusters of physiological effect. By grouping the nuclear receptors in this effect-based way, researchers can derive testable hypotheses about particular physiological (and pathological) pathways with which any given receptor might be predominately involved. The first and so far only attempt to organize the nuclear hormone receptor superfamily by this method (Bookout et al. 2006) produced two initial, general "paradigms" of (I) reproduction, development, and growth versus (II) nutrient uptake, metabolism, and excretion. These two paradigms were then each divided into three further groups called "clusters," for a total of six clusters within the superfamily and one lone receptor, PNR, which is only expressed in one type of cell and thus cannot be part of a suite of cell types. The six clusters are each labeled by the physiologic pathways they presumably affect: (IA) steroidogenesis; (IB) reproduction and development; (IC) central nervous system with circadian and basal metabolism; (IIA) bile acids and xenobiotic metabolism; (IIB) lipid metabolism; and (IIC) energy homeostasis.

\section{Complexity}

So, what do we have here? We have some complicated scientific practice based on some complex scientific objects. We can expect, I think, some of the divergent classificatory organization presented in the prior section to dissolve as further work occurs. For example: it is possible that there is one best way of organizing species-specific nuclear receptors by activation typology, rather than many — and that the scientific community might eventually settle on what that typology is. We could also eliminate some of the divergent classificatory organization showcased above by being more consistent about how we generate phylogenies of the superfamily. Species-specific phylogenies (focusing only on the nuclear receptors found in humans, for instance) will naturally diverge from more inclusive ones (which can include all those nuclear receptors found in human, mice, rat, drosophila and more), and such classificatory divergence is simply a product of different 
things being classified differently, rather than the same things being classified differently.

But a substantive portion of the divergent classificatory organization found here is ineliminable. This is because nuclear receptors are complex objects. We tend to think of objects of a kind as sharing a cluster of their properties and capacities (the essential and / or intrinsic ones, if we are metaphysically so-inclined) with others of their kind. But complex objects like nuclear receptors share multiple, distinct clusters of their properties and capacities with several divergent kinds, and they belong to each. When such complex objects are being classified, even scientifically, divergent classificatory organization results. Researchers have incentive to generate any and all those classification systems which grant them reliable, fruitful inferences. Patterns of inference bearing on certain themes (which might be called 'affordances ${ }^{23}$ ) do tend to be differentially valuable from different perspectives — even within a narrow, interdisciplinary context. But this interest-relativity is not what generates or explains the naturally divergent kinds; rather, it motivates and rewards our recognition of them. To be pithy, human interests explain the kinding (à la Kendig 2016a, 2016b), but not the kinds. ${ }^{24}$ Consider the following illustration:

\footnotetext{
${ }^{23}$ À la Gibson (1977).

${ }^{24}$ Hence, a compatibilist account of complex scientific kind-generation is required-one that combines naturalism with conventionalism. Thanks to Dresow and Love (2018) for suggesting the 'compatibilist' terminology.
} 


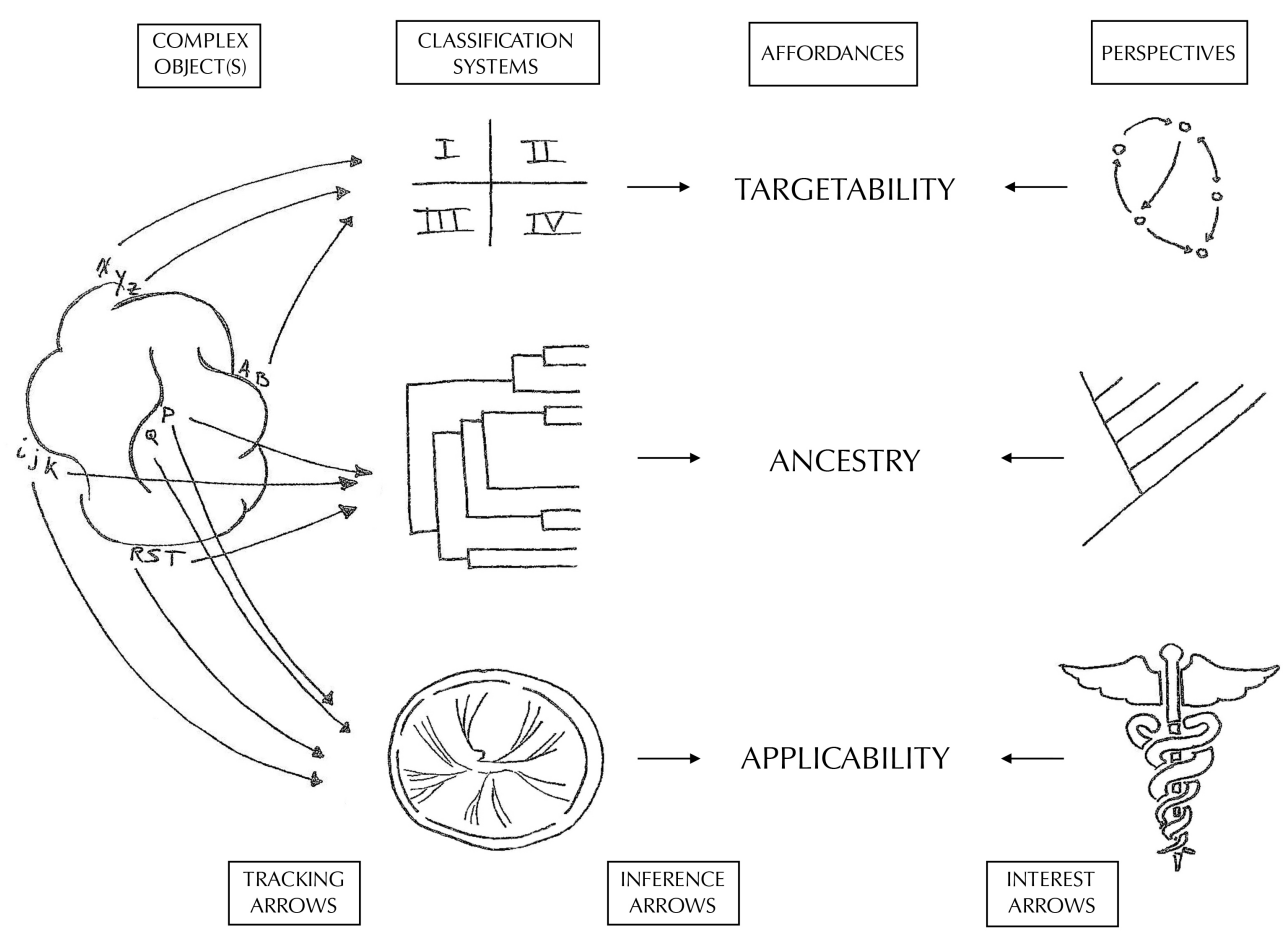

Fig. 5 How nuclear receptors (as complex objects) beget a trio of divergent classification systems for organizing the nuclear hormone receptor superfamilyaffording inferences to things differently valued from different perspectives. Drawings by Adam Streed.

Note that this is not a case of a group of object-kinds clustering closer together or farther apart (based on how many properties and capacities they share) on one map showing multiple clustercenters. This is a case in which the same group of object-kinds clusters differently (to different degrees and with different neighbors) on three divergent styles of map_each with multiple, unique cluster-centers. The complexity is there, in the kinds, to be divergently mapped.

What is complexity, such that it can produce this sort of classificatory divergence? In a helpful analysis of complex systems, Sandra D. Mitchell (2009) identifies four characteristic features: (a) multilevel organization; (b) multicomponent causal interaction; (c) contextual plasticity; and (d) evolved contingency. Although Mitchell's account is designed for complex systems, I think that it 
can be applied to complex objects as well. ${ }^{25}$ Nuclear receptors certainly exhibit all four of these features; these features are what generate the divergent classificatory organization of the superfamily; and the fourth feature in particular (evolved contingency) is what prevents the unification of these divergent taxonomies from even being a sensible aim. In Mitchell's $(2003,2009)$ terms, integration —as opposed to unification (à la Kitcher 1981)—is the best we can hope for here.

Let me quickly substantiate my claim that nuclear receptors are complex objects according to Mitchell's four features. First is (a) multilevel organization, which occurs when there are different levels of organization within one complex object. Nuclear receptors, as proteins, are polypeptides: macromolecules composed of multiple amino acids linked by peptide and other bonds. Proteins are not just chains of amino acids, however. Comprehensive protein structure is divided into four different levels: primary structure—amino acid sequence, producing chains; secondary structurelocal bond formation between amino acids, producing shapes like turns and sheets; tertiary structure-additional interactions between elements scattered throughout the molecule, completing overall conformation; and quaternary structure-multiple-molecule shape formation, producing complexes. Nuclear receptors exhibit the first three of these four levels: they have primary through tertiary multilevel organization.

Next is (b) multicomponent causal interaction. Again, nuclear receptors in particular and proteins in general are large molecules composed of amino acids. These amino acids are covalently linked into a chain via peptide bonds, but also contorted due to a host of other chemical interactions that occur among the amino, carboxyl, and variable R-groups, the shapes that clusters of these groups form, and even the various shapes formed by separate sequences. So, these proteins have

${ }^{25} \mathrm{It}$ is common to associate complexity with systems and simplicity with objects. But this is a problematic tendency, as these associations can come apart. There are simple systems and complex objects, so it is a mistake to think of systems as constitutively complex and objects as constitutively simple. 
primary components ${ }^{26}$ (amino acids) which causally interact to form secondary components (turns and sheets) which causally interact to form tertiary components (completing their overall conformational structure and determining their interactions with other molecules).

Then comes (c) contextual plasticity, which for the nuclear receptors (and many other proteins) is realized via their different dynamics in different contexts. Nuclear receptors are complex objects which can change their shape. They can bend and turn, fold and twist, pick things up and drop them, even attract and repel certain things. Nuclear receptors are dynamic and contextually plastic, as are most proteins.

Finally there is (d) evolved contingency. One of the strongest constraints on evolution is that it must make do with the tools at hand. And so proteins in general and nuclear receptors in particular have often evolved to do different things in different places. Nuclear receptors have a complex structure that allows them to accomplish many different functions. But another aspect of the contingency of evolution is that different structures can evolve to accomplish similar functions. Different proteins can do similar things in different ways. For instance, DNA binding has evolved to occur by several methods. There are triple-zinc-finger motifs and helix-turn-helix motifs, both of which allow proteins with these motifs to form a complex with DNA. In a classification of proteins by function, proteins exhibiting either of these motifs might be grouped together. But in a classification of proteins by either structure or ancestry, they would not be grouped together, as these two motifs have very distinct structures as well as different evolutionary histories. This brings us back to the main topic under discussion: naturally divergent classificatory organization of nuclear receptors, due to their status as complex objects.

\footnotetext{
${ }^{26}$ Perhaps better described as parts rather than components, since we are talking about objects rather than systems.
} 


\section{Application of the Case}

To briefly refresh: nuclear receptors are complex multiple-domain proteins that act both as receptors and as transcription factors. Nuclear receptors tend to be expressed in many different cell types and often do different things in each. Some nuclear receptors do similar things in different ways. Different parts (such as the ligand-binding and DNA-binding domains) of individual receptors have distinct evolutionary histories. As a result of this multi-level, multi-component, multi-function, and multi-evolutionary history, there are three different kinds of system-procedurally typological, phylogenetic, and effect-based typological—for classifying the nuclear receptors in the superfamily.

These distinct kinds of systems for organizing the nuclear hormone receptor superfamily each place the nuclear receptors in different groups with different neighbors, and each tend to grant fruitful, reliable inferences to certain affordances, differentially valuable from different perspectives. ${ }^{27}$ There is no one true hierarchy to be found, now or ever, among these nonetheless natural kinds.

I have deployed an extremely technical and detailed example in order to clearly establish the scientific legitimacy of my case, and to dispel any concerns that divergent classificatory organization inevitably stems from either non-epistemic human interests or befuddled attempts to scientifically

\footnotetext{
${ }^{27}$ For anyone not yet sick of the science: tracking (first) the structural properties and activation-plusbinding capabilities of nuclear receptors generates procedurally typological classifications of the superfamily which tend to afford successful inferences to targetability, which is especially important from a biomechanical perspective. Tracking (second) the sequential properties and alignment capabilities of nuclear receptors generates alternative phylogenetic classifications of the superfamily which tend to afford successful inferences to ancestry, which is especially important from an evolutionary perspective. Tracking (third, and finally) the gene expression properties and physiological capabilities of nuclear receptors generates effect-based typological classifications of the superfamily which tend to afford successful inferences to applicability, which is especially important from a biomedical perspective. All three of these perspectives are valuable within the community of researchers who study the nuclear receptors: reliable patterns of inference to targetability allow for ligands to be discovered or designed, materials to be synthesized, and experiments to be run; reliable patterns of inference to ancestry allow for homology inferences to be made, and for information known about one nuclear receptor to be potentially applied to other, evolutionarily related receptors; and reliable patterns of inference to applicability help to direct, apply, and market early-stage or "basic" biomedical research towards more "applied" translational and clinical research.
} 
classify non-scientific kinds (as one might think happens with the category 'poison'). The story of the surprising detection of the nuclear receptors, with gradual elucidation of the nuclear hormone receptor superfamily, is a paradigmatic narrative of scientific progress_one incorporating many unanticipated moments of puzzlement, conjecture, validation, explanation and prediction along the way. These kinds are scientific in origin and so is their classificatory divergence.

But is nuclear receptor complexity, the generator of their classificatory divergence, actually a crucial liability here? One might be tempted to venture-even granting their status as scientific kinds - that nuclear receptors and the nuclear hormone receptor superfamily are altogether just too complex to be considered as natural kinds, properly understood. Perhaps the claim would go as follows: "if the objects that you are considering are this complex, if they have clusters of features that differentially associate with one another in these different ways, then there is just not enough linking of properties here- there is too much disassociation-for these groups to achieve natural kind status." Now consider what this move implies for arrangement of the elements—the example par excellence of natural kinds, properly understood.

Elements have this sort of complexity, although it is often ignored in philosophical discourse, which tends to focus on the straightforward characterization of elements by atomic number, along with the sharp individuation of atoms into determinate element kinds. Attending to organization instead, we should note that element kinds can (of course) be sorted serially, by lining them up in one long sequence (by atomic number). But that is not (only) what the Periodic Table does, because there are other relevant taxonomies of the elements to represent and deploy. Vertically (in columns), elements are clustered by group—such as alkali metals, or noble gases— membership in which is determined by valence (or how many electrons are available for bonding, in what kind of outermost shell). Horizontally (in rows), elements are clustered by block-such as fblock or p-block - membership in which is determined by atomic orbital type (or how electrons are 
configured, in what kind of outermost shell). In each of these taxonomies, a different selection of properties and capacities of each element are picked out, putting them in a new group with different neighbors. Serially, the nearest neighbors to argon (atomic number 18) are chlorine (atomic number 17) and potassium (atomic number 19), but argon is a noble gas while chlorine is a halogen and potassium is an alkali metal. Argon and chlorine are p-block members (with a lobed and principal outermost shell), while potassium is an s-block member (its outermost shell is spherical and sharp). Obviously, these overlapping, non-nested groups cannot be unified into a single cohesive hierarchy. The brilliance of "the" Periodic Table lies precisely its ability to integrate and communicate these divergent, crosscutting taxonomies of the elements regardless. ${ }^{28}$

I did not want to rely on the chemical elements to make my overall case, because there are many confounding and non-scientific intuitions about them. I refer to them here only to point out that they too are complex objects, and correspondingly they permit of divergent classificatory organization. Any theorist who wants to treat such complexity as prohibitive of natural kind status will have to be willing to strike chemical kinds like 'the noble gases' and 'the s-block elements' from their list of candidate natural kinds. Not even Ellis, the paradigmatic scientific essentialist, is willing to bite this bullet. ${ }^{29}$ Given the scientific status_-and proven success_-of such kinds, I recommend striking the hierarchic thesis instead.

Still, perhaps there are some natural kind theorists (unlike Ellis) willing to abandon the sblock elements and the noble gases, along with the type I nuclear receptors and the PPAR nuclear hormone receptor family, as candidate natural kinds-merely on the basis of demonstrated

\footnotetext{
${ }^{28}$ Really, there are many-precisely because of the different affordances they differentially allow. ${ }^{29} \mathrm{He}$ wants his account to allow for 'cupric compounds' and 'sulfates' to count as natural kinds, despite that they share copper sulfate as a common member while neither kind is a species of the other $(2001,56 n 2)$. And such kinds are less foundational to chemistry than the columns, rows, and blocks of the Periodic Table, surely.
} 
classificatory divergence. Presumably, only the elements themselves and the serially ordered list of elements (an arrangement lacking much of what the actual, Mendeleevian Periodic Table has to offer), and relatedly, the nuclear receptors themselves and the superfamily itself, would qualify as natural kinds from this point of view. Unfortunately, not even those lower- and higher-level groupings would remain; they are not themselves exempt from the sort of classificatory divergence I demonstrated at mid-level. I merely held those levels fixed for the purposes of this discussion, so that the existence of mid-level divergent classificatory organization could be made crystal clear.

I can shatter that clarity. Take a species-specific nuclear receptor like human PPAR $\gamma$, for example. To which kind does it more naturally belong: that of other human PPARs (like human PPAR $\alpha$ and human PPAR $\beta$ ), or that of non-human, other-species-specific PPAR $\gamma$ s (like mouse PPAR $\gamma$ and rat PPAR $\gamma$ )? Or, take the human nuclear hormone receptor superfamily: where should it be placed? Is the proper genus for this species all the rest of the nuclear receptors found in other organisms, or is it all the rest of the transcription factors found in humans? We can do this with the elements and the Periodic Table, too. There are fifteen known isotopes of carbon (from ${ }^{8} \mathrm{C}$ to ${ }^{22} \mathrm{C}$ ). ${ }^{30}$ Two of them are naturally-occurring stable isotopes $\left({ }^{12} \mathrm{C}\right.$ and $\left.{ }^{13} \mathrm{C}\right)$. There is one naturally-occurring radioisotope $\left({ }^{14} \mathrm{C}\right)$. Which kind is most "natural": ${ }^{14} \mathrm{C}$ with just the other two naturally-occurring isotopes of carbon, ${ }^{12} \mathrm{C}$ and ${ }^{13} \mathrm{C}$ ? Or is it ${ }^{14} \mathrm{C}$ with the other carbon radioisotopes, none of which are naturally occurring? Or perhaps the "natural" kind is just all the carbon isotopes, regardless of whether they occur naturally, and are radioactive? Maybe ${ }^{14} \mathrm{C}$ is most "naturally" grouped with other naturally-occurring radioisotopes, none of which are other carbons? Speaking of this, which is a more "natural" way of arranging all the isotopes of every element: sorting them serially by number of protons, and then within those groups, by number of neutrons (in both cases, from lowest to

\footnotetext{
${ }^{30}$ Or see Hacking's discussion of phosphorous (2007b, 223-224).
} 
highest)? Or sorting them serially by (temporal) half-life_-say, from most to least stable? Not even isotopes of an element have to be neighbors in what are nonetheless perfectly natural scientific groupings. ${ }^{31}$

So this austere approach does not, after all, preserve the natural kindhood of (for instance) the elements themselves and the nuclear hormone receptor superfamily, by sacrificing the natural kindhood of (for instance) the noble gases and the mechanistic type II nuclear receptors. Very little at all can be saved by this approach. What little can be saved will be specified in the conclusion; but first, quick discussion of a potential worry.

\section{A Note About Success}

It is currently somewhat fashionable to appeal to success in science, or achievement of epistemic aims, for certification of which natural kinds are the genuine ones (e.g., Magnus 2012; Franklin-Hall 2015). Someone with this style of view might be concerned about the existence of classificatory divergence-if one also thought that such divergence was likely to inhibit scientific success, or epistemic achievement. (It is common to presume that having different classification schemas for the same set of objects will hinder investigation. ${ }^{32}$ ) But at least when complex objects are involved, classificatory divergence can actually aid in scientific investigation. As the case of the nuclear hormone receptor superfamily shows, divergent classificatory organization can even be used as a tool for discovery (à la LaPorte 2004; see also Havstad 2014 for discussion of precisely this case).

Again, nuclear receptors are incredibly complex objects. There are many of them. Each has myriad properties and capabilities. Most do different things in different cell types. Their structural

\footnotetext{
${ }^{31}$ Please see LaPorte (2004), Hendry (2006), and Havstad (2018)_among others_-for additional, philosophical discussion of isotope classification. See Kragh (2000) for an historical discussion of how close we came to treating isotopes as the fundamental elements of the periodic table.

${ }^{32}$ E.g., "[u]sers of different schemes of representation may find it difficult to coordinate their languages" (Kitcher 2001, 47).
} 
and functional similarities often diverge. They have fractured evolutionary histories. Unsurprisingly, this complexity creates special challenges for nuclear receptor research. Orphans lack known ligands - making them almost impossible to intentionally activate and study using typical methods. Nuclear receptor gene expression generally occurs in a variety of cell types—so gene expression screening tends to produce information overload. Nuclear receptor activity tends to be widespread, diffuse, and diverse in terms of effects—so knockout experiments are often lethal, or they tend to produce conflicting results. Finally, nuclear receptors are active in so many distinct physiological pathways, and their malfunction contributes to so many distinct pathologies, that in many cases it would be massively wasteful — in others it would be impossible — to attempt to elucidate the influence of any particular nuclear receptor on physiology by simply going down the list of things that other nuclear receptors have been determined to affect, in each case applying the particular techniques and specific tests from that sphere to the nuclear receptor of interest.

But with a variety of systems for relating the nuclear receptors to one another-for hunting out potential connections that are suggested by a combination of procedural, phylogenetic, and / or effect-based groupings—some progress can occasionally be made. Myriad possibilities for investigation can be winnowed down, suggesting a few promising candidates among a nearly unlimited number of potential research projects: those that are suggested by multiple associations in distinct classification systems - ideally, those that are suggested mechanistically, evolutionarily, and physiologically. The complexity of the nuclear receptors both generates the divergent classification systems for organizing the superfamily, and necessitates the integration of these classification approaches. Scientists are facing a plethora of possible paths to pursue, all the while serving multiple masters; but considering the different relationships suggested by various classifications of the superfamily can help to highlight which are the most promising avenues for future research. In such complex cases, unique hierarchical organization is neither necessary nor sufficient for 
successful scientific investigation.

\section{Concluding Remarks}

Talk of natural kinds abounds, especially in the philosophy of science. ${ }^{33}$ Many in this grand philosophical tradition have thought that such kinds, properly understood, must permit of only one arrangement - that there is a uniquely true, hierarchical ordering of the (strict) natural kinds. This way of thinking about natural kinds - in terms of one true taxonomy - is itself a natural extension of thinking about the distinction between natural and artificial kinds as the following have:

And the Maxim by which all Systems professing to be natural must be tested is this: - that the arrangement obtained from one set of characters coincides with the arrangement obtained from another set. (Whewell 1840, Book I, 521; italics original)

The rational core of the distinction between natural and artificial classifications is suggested by the consideration that in so-called natural classifications the determining characteristics are associated, universally or in a high percentage of all cases, with other characteristics, of which they are logically independent. (Hempel 1952, 53)

If the new essentialists are right, then things must act in ways that depend on their intrinsic properties or structures, and on how these things stand in relation to other things. Consequently, it is a necessary truth that things of the same natural kind must always behave in exactly the same way (or range of ways with the same probabilities), if they are in circumstances of the same kind. (Ellis 2002, 135) (4 $^{34}$

${ }^{33}$ This is an area in which so much excellent scholarship has been done that it is almost impossible to do justice to the task of appropriately citing the literature. I am particularly indebted to the following works: Nagel 1929; Quine 1969; Thomason 1969; Putnam 1970, 1973, 1975; Kripke 1972/1980; Mellor 1977; Kitts and Kitts 1979; Dupré 1981, 1983, 1993, 2001, 2002; Mark Wilson 1982; Kitcher 1984, 1993, 2001; de Sousa 1984; Devitt \& Sterelny 1987; Ruse 1987; Wilkerson 1988, 1993; Meyer 1989; Hacking 1990, 2007a, 2007b; Boyd 1991, 1999; Khalidi 1993, 1998, 2013, 2018 ; Elder 1994, 2008; Griffiths 1996, 1999; Robert A. Wilson 1996, 1999; Millikan 1999; Stanford and Kitcher 2000; Ellis 2001, 2002, 2005; LaPorte 2004; Mumford 2005; Slater 2005, 2015; Wikforss 2005; Hendry 2006, 2012; Reydon 2006; Barrett 2007; Chakravartty 2007; Lowe 2007; Rieppel 2007 , 2010; Soames 2007; Wilson, Barker, and Brigandt 2007; Devitt 2008; Brigandt 2009; Beebee and Sabbarton-Leary 2010; Dumsday 2010, 2012; Ruphy 2010; Campbell, O'Rourke, and Slater 2011; Bird 2012, 2018; Leonelli 2012; Magnus 2012, 2014, 2018; Needham 2012; Danks 2015; Ereshefsky and Reydon 2015; Franklin-Hall 2015; Tahko 2012, 2015; Kendig 2016a, 2016b; Ludwig 2017; Bursten 2018; Häggqvist and Wikforss 2018; Longy 2018; McFarland 2018. I sincerely apologize to anyone whom I should have cited but did not.

${ }^{34}$ Again, Ellis wants his account to allow for 'cupric compounds' and 'sulfates' to count as natural kinds, even though they share copper sulfate as a common member while neither kind is a species of 
Any member of a category of objects that shares causal properties with other members, either strictly in the case of essence kinds, or more loosely in the case of cluster kinds, can be expected to be similar and to behave in similar ways in similar circumstances. (Chakravartty $2007,170)^{35}$

Two types of materials that are similar deep down will have many properties in common. (Longy 2018, 1482)

Collectively, this way of thinking-one which relates the naturalness of one grouping to the artifice of another-mistakes similarity for sameness. Two types of materials that are the same, deep down, will certainly have many properties in common. Two types of materials that are similar, deep down, will have some properties in common. If the two types of similar materials are very similar, then they may indeed have many properties in common. Or, if the two types of materials are very simple, then they may have most of their properties in common (as they might not have that many properties to begin with). But if the two types of material are complex, then the fact that they are similar will not necessarily tell you that they have many properties in common. Nor will their sort of similarity necessarily be trivial, and kind-talk pertaining to them be artificial.

The ultimate aim of this paper was to demonstrate that, due to the existence of complexity in nature, even the natural kinds permit of more than one hierarchical arrangement - that there is more than one taxonomy of natural kinds, properly understood. I deployed the case of the nuclear hormone receptor superfamily — an undeniably complex and irrefutably scientific grouping — to achieve my aim. I showed that-despite clarity and consensus about how to characterize the nuclear

the other $(2001,56 \mathrm{n} 2)$. I do not know how to reconcile this aim with the quote above. Copper sulfate and copper oxide are both cupric compounds, but they certainly do not behave the same way (or range of ways) in circumstances of the same kind. For instance: copper oxide is not a sulfate. ${ }^{35}$ Chakravartty also writes: "In the case of essence kinds, definitional generalizations describing members in terms of their essential properties will be exceptionless, but the same cannot be said of behavioral generalizations. Essences are no guarantee of uniform behavior among the members of a kind, even in exactly similar circumstances" $(2007,173)$. So, this author is only sometimes guilty of this misunderstanding. 
receptors, and how to individuate them — the status of the nuclear receptors as complex objects produces ineliminable classificatory divergent organization, even in an intradisciplinary context. And I could play this game in other arenas: with other transcription factors, proteins, molecules, atoms, or particles. Appealing to the sort of complexity that nuclear receptors have as a blanket prohibitor of natural kind status means entities like the elements are not natural kinds either.

Only if nature were limited to the very simplest assortment of objects and properties would science correspondingly be restricted to just one hierarchical arrangement of its natural kinds. Imagine that there was only one kind of property in existence, $\mathrm{P}^{1}$, and that all objects had only this property in discrete but variable amounts—all objects could be represented as $1 \mathrm{P}^{1}, 2 \mathrm{P}^{1}, 3 \mathrm{P}^{1}, \ldots n \mathrm{P}^{1}$. This is a state of nature which plausibly permits of just one hierarchical arrangement of its natural kinds (a serial one). However, if any contrastive interactions between instances of the property $\mathrm{P}^{1}$ occur-say, if instances of the property function in paired sets differently than they do in unpaired sets — then multiple taxonomic arrangements already begin to suggest themselves. Objects with an even number of property instances $\left(2 \mathrm{P}^{1}, 4 \mathrm{P}^{1}\right.$, etc.) on the one hand, and objects with an odd number of property instances $\left(1 \mathrm{P}^{1}, 3 \mathrm{P}^{1}\right.$, etc.) on the other, might in each case be more "natural" neighbors with one another than with their serial-number neighbors. Another way to think about this is via the introduction of a second property type, $\mathrm{P}^{2}$. As soon as we have an assortment of objects like $1 \mathrm{P}^{1}, 2 \mathrm{P}^{1}, 1 \mathrm{P}^{2}$, and $2 \mathrm{P}^{2}$, we can ask: which arrangement of kinds is more "natural"? That which groups $1 \mathrm{P}^{1}$ with $1 \mathrm{P}^{2}$, while grouping $2 \mathrm{P}^{1}$ with $2 \mathrm{P}^{2}$ ? Or that which groups $1 \mathrm{P}^{1}$ with $2 \mathrm{P}^{1}$, while grouping $1 \mathrm{P}^{2}$ with $2 \mathrm{P}^{2}$ ? Naturally crosscutting categories occur at extremely low levels of complexity; all you really need is variation along two disassociating dimensions.

In other words: it takes very, very little in the way of complexity to kill hierarchy. Such complexity is evident in nature. I suppose one could insist that the only "natural" kinds are those 
which do not permit of such hierarchical flexibility. But this view mistakes sameness as the standard for similarity, and treats an epistemic ideal—simplicity—as the criterion for what is categorically real.

Acknowledgments. I am grateful to Nancy Cartwright and Sandy Mitchell for inspiring this work, and for supporting me while doing it. I am also grateful to Hasok Chang and Jim Griesemer for seeing value in my case study, even before I was capable of articulating the nature of that value. Thanks to Ken Aizawa and Tuomas Tahko for inviting me to attend the Rutgers-Bristol Workshop on the Metaphysical Unity of Science in June 2019; and thank you to all the workshop participants for engaging. Finally, thanks to Kathleen Connelly, Adrian Currie, John Dupré, Alison McConwell, Aaron Novick, Adam Streed, and three anonymous reviewers for helpful feedback on drafts.

\section{Works Cited}

Arthur, Wallace. 2002. "The Emerging Conceptual Framework of Evolutionary Developmental Biology." Nature 451(6873): 757-764.

Barrett, Jeffrey A. 2007. "Dynamic Partitioning and the Conventionality of Kinds." Philosophy of Science 74: 527-546.

Bechtel, William, and Adele Abrahamsen. 2005. "Explanation: A Mechanist Alternative." Studies in History and Philosophy of Biology and Biomedical Science 36: 421-441.

Beebee, Helen. 2013. "How to Carve Across the Joints in Nature Without Abandoning KripkePutnam Semantics." In Metaphysics and Science, eds. Stephen Mumford and Matthew Tugby, 141-163. Oxford: Oxford University Press.

Beebee, Helen, and Nigel Sabbarton-Leary. 2010. The Semantics and Metaphysics of Natural Kinds. New York: Routledge.

Bird, Alexander. 2012. "Referring to Natural Kind Thingamajigs, and What They Are: A Reply to Needham." International Studies in the Philosopby of Science 26(1): 103-109.

Bird, Alexander. 2018. “The Metaphysics of Natural Kinds.” Synthese 194(4): 1397-1426.

Bookout, Angie L., Yangsik Jeong, Michael Downes, Ruth T. Yu, Ronald M. Evans, and David J. Mangelsdorf. 2006. Anatomical Profiling of Nuclear Receptor Expression Reveals a Hierarchical Transcriptional Network. Cell 126(4): 789-799.

Boyd, Richard. 1991. "Realism, Anti-Foundationalism and the Enthusiasm for Natural Kinds." Philosophical Studies 61: 127-148.

Boyd, Richard. 1999. "Kinds, Complexity, and Multiple Realization.” Philosophical Studies 95: 67-98.

Brigandt, Ingo. 2009. "Natural Kinds in Evolution and Systematics: Metaphysical and Epistemological Considerations." Acta Biotheoretica 57: 77-97.

Burge, Tyler. 1993. "Concepts, Definitions, and Meaning." Metaphilosophy 24(4): 309-325. 
Bursten, Julia. 2018. "Smaller than a Breadbox: Scale and Natural Kinds." British Journal for the Philosophy of Science 69: 1-23.

Campbell, Joseph Keim, Michael O’Rourke, and Matthew H. Slater (eds.). 2011. Carving Nature at Its Joints: Natural Kinds in Metaphysics and Science. Cambridge, MA: MIT Press.

Chakravartty, Anjan. 2007. A Metaphysics for Scientific Realism: Knowing the Unobservable. Cambridge: Cambridge University Press.

Cracraft, Joel. 1983. "Species Concepts and Speciation Analysis." In Current Ornithology, Volume 1, ed. Richard Johnston, 159-187. New York: Plenum Press.

Craver, Carl F., and Lindley Darden. 2013. In Search of Mechanisms: Discoveries across the Life Sciences. Chicago: University of Chicago Press.

Danks, David. 2015. "Goal-dependence in (scientific) ontology.” Synthese 192: 3601-3616.

de Sousa, Ronald. 1984. "The Natural Shiftiness of Natural Kinds." Canadian Journal of Philosophy XIV(4): 561-580.

Detera-Wadleigh, Sevilla D., and Thomas G. Fanning. 1994. "Phylogeny of the Steroid Receptor Superfamily." Molecular Phylogenetics and Evolution 3(3): 192-205.

Devitt, Michael. 2008. "Resurrecting Biological Essentialism.” Philosophy of Science 75: 344-382.

Devitt, Michael and Kim Sterelny. 1987. Language and reality: An introduction to the philosophy of language. Cambridge, MA: MIT Press.

Dresow, Max, and Alan C. Love. 2018. "Review of Catherine Kendig, ed. Natural Kinds and Classification in Scientific Practice." HOPOS Spring 2018: 217-222.

Dumsday, Travis. 2010. "Natural Kinds and the Problem of Complex Essences." Australasian Journal of Philosophy 88(4): 619-634.

Dumsday, Travis. 2012. "A New Argument for Intrinsic Biological Essentialism.” Australasian Journal of Philosophy 88: 619-634.

Dupré, John. 1981. "Natural Kinds and Biological Taxa.” The Philosophical Review XC(1): 66-90.

Dupré, John. 1983. “The Disunity of Science.” Mind XCII: 321-346.

Dupré, John. 1993. The Disorder of Things: Metaphysical Foundations for the Disunity of Science. Cambridge, MA: Harvard University Press.

Dupré, John. 2001. "In Defense of Classification." Studies in History and Philosophy of Biology and Biomedical Science 32: 203-219.

Dupré, John. 2002. “Is 'Natural Kind' a Natural Kind Term?” The Monist 85(1): 29-49.

Dupré, John. 2006. "Scientific Classification.” Theory, Culture, \& Society 23(2-3): 30-32.

Elder, Crawford L. 1994. "Higher and Lower Essential Natures." American Philosophical Quarterly 31(3): 255-265.

Elder, Crawford L. 2008. "Biological Species Are Natural Kinds." The Southern Journal of Philosophy XLVI: 339-362.

Ellis, Brian. 2001. Scientific Essentialism. Cambridge: Cambridge University Press.

Ellis, Brian. 2002. The Philosophy of Nature: A Guide to the New Essentialism. Montreal, QC: McGillQueen's University Press.

Ellis, Brian. 2005. "Physical Realism." Ratio XVIII: 371-384.

Ereshefsky, Marc. 1992. "Eliminative Pluralism." Philosophy of Science 59: 671-690.

Ereshefsky, Marc, and Thomas A. C. Reydon. 2015. "Scientific Kinds." Philosophical Studies 172(4): 969-986.

Evans, Ronald M. 1988. "The Steroid and Thyroid Hormone Receptor Superfamily." Science 240: 889-895.

Evans, Ronald M., Cary Weinberger, Stanley M. Hollenberg, and Michael G. Rosenfeld. 1986. "Structure and Expression of Human Glucocorticoid Receptor cDNA: A Trans-Acting Factor Related to the c-erbA Protooncogene Family." Journal of Molecular and Cellular Biology 5: 
63.

Feduccia, Alan. 2013. "Bird Origins Anew." The Auk 130(1): 1-12.

Franklin-Hall, L. R. 2015. "Natural Kinds as Categorical Bottlenecks." Philosophical Studies 172: 925948.

García-Sancho, Miguel. 2010. “A New Insight into Sanger’s Development of Sequencing: From Proteins to DNA, 1943-1977.” Journal of the History of Biology 43(2): 265-323.

Gibson, James J. 1997. “The Theory of Affordances." In Perceiving, Acting, and Knowing: Toward an Ecological Psychology, ed. Robert Shaw and John Bransford, 67-82. Hillsdale, NJ: Lawrence Erlbaum.

Giguère, Vincent, Na Yang, Prudimar Segui, and Ronald M. Evans. 1988. "Identification of a New Class of Steroid Hormone Receptors." Nature 331(6151): 91-94.

Glennan, Stuart. 2002. "Rethinking Mechanistic Explanation.” Philosophy of Science 69: S342-S353.

Green, Stephen, Philippe Walter, Vijay Kumar, Andrée Krust, Jean-Marc Bornert, Patrick Argos, and Pierre Chambon. 1986. "Human Oestrogen Receptor cDNA: Sequence, Expression, and Homology to v-erb-A." Nature 320(6058): 134-139.

Griffiths, Paul E. 1996. "Darwinism, Process Structuralism, and Natural Kinds." Philosophy of Science 63: S1-9.

Griffiths, Paul E. 1999. "Squaring the Circle: Natural Kinds with Historical Essences.” In Species: New Interdisciplinary Essays, ed. Robert A. Wilson, 209-228. Cambridge, MA: MIT Press.

Gronemeyer, Hinrich, Jan-Åke Gustafsson, and Vincent Laudet. 2004. "Principles for Modulation of the Nuclear Receptor Superfamily." Nature Reviews Drug Discovery 3(11): 950-964.

Hacking, Ian. 1990. “A Tradition of Natural Kinds.” Philosophical Studies 61: 109-126.

Hacking, Ian. 2007a. "The Contingencies of Ambiguity.” Analysis 67(4): 269-277.

Hacking, Ian. 2007b. "Natural Kinds: Rosy Dawn, Scholastic Twilight." Royal Institute of Pbilosopby Supplements 61: 203-239.

Häggqvist, Sören, and Åsa Wikforss. 2018. "Natural Kinds and Natural Kind Terms: Myth and Reality." British Journal for the Philosophy of Science 69(4): 911-933.

Hardimon, Michael O. 2003. "The Ordinary Concept of Race." Journal of Philosophy C(9): 437-455.

Harrington, Charles Robert, and George Barger. 1927. "Chemistry of Thyroxine: Constitution and Synthesis of Thyroxine." Biochemical Journal 21: 169-183.

Hart, H. L. A. 1961. The Concept of Law. New York: Oxford University Press.

Havstad, Joyce C. 2014. Biochemical Kinds and Selective Naturalism. UC San Diego: PhD Thesis.

Havstad, Joyce C. 2016. "Protein Tokens, Types, and Taxa." In Natural Kinds and Classification in Scientific Practice, ed. Catherine Kendig, 74-86. London: Routledge.

Havstad, Joyce C. 2018. "Messy Chemical Kinds.” British Journal for the Philosophy of Science 69: 719_ 743.

Hempel, Carl G. 1952. Fundamentals of Concept Formation in Empirical Science. Chicago, IL: University of Chicago Press.

Hendry, Robin F. 2006. "Elements, Compounds, and Other Chemical Kinds." Philosophy of Science 75: 864-875.

Hendry, Robin F. 2012. "Chemical Substances and the Limits of Pluralism." Foundations of Chemistry 14: 55-68.

Hollenberg, Stanley M., Cary Weinberger, Estelita S. Ong, Gail Cerelli, Anthony Oro, Roger Lebo, E. Brad Thompson, Michael G. Rosenfeld, and Ronald M. Evans. 1985. "Primary Structure and Expression of a Functional Human Glucocorticoid Receptor of cDNA." Nature 318(6047): 635-641.

Jensen, Elwood, and Herbert I. Jacobson. 1962. "Basic Guides to the Mechanism of Estrogen Action." Recent Progress in Hormone Research 18: 387-414. 
Kendall, Edwin C. 1915. "The Isolation in Crystalline Form of the Compound Containing Iodin, Which Occurs in the Thyroid." Journal of the American Medical Association LXIV: 2042-2043.

Kendig, Catherine. 2016a. "Editor's Introduction: Activities of Kinding in Scientific Practice." In Natural Kinds and Classification in Scientific Practice, ed. Catherine Kendig, 1-13. London: Routledge.

Kendig, Catherine. 2016b. "Homologizing as Kinding." In Natural Kinds and Classification in Scientific Practice, ed. Catherine Kendig, 106-125. London: Routledge.

Khalidi, Muhammad A. 1993. "Carving Nature at the Joints." Philosophy of Science 60: 100-113.

Khalidi, Muhammad A. 1998. "Natural Kinds and Crosscutting Categories." Journal of Philosophy 95(1): 33-50.

Khalidi, Muhammad A. 2013. Natural Categories and Human Kinds: Classification in the Natural and Social Sciences. Cambridge: Cambridge University Press.

Khalidi, Muhammad A. 2018. "Natural Kinds as Nodes in Causal Networks." Synthese 195: 1379_ 1396.

Kitts, David B. and David J. Kitts. 1979. "Biological Species as Natural Kinds." Philosophy of Science 46: 613-622.

Kitcher, Phillip. 1981. "Explanatory Unification.” Philosophy of Science 48: 507-531.

Kitcher, Phillip. 1984. "Species." Philosophy of Science 51: 308-333.

Kitcher, Phillip. 1993. The Advancement of Science: Science without Legend, Objectivity without Illusions. New York: Oxford University Press.

Kitcher, Phillip. 2001. Science, Truth, and Democracy. Oxford: Oxford University Press.

Kragh, Helge. 2000. "Conceptual Changes in Chemistry: The Notion of a Chemical Element, ca. 1900-1925." Studies in History and Philosophy of Modern Physics 31(4): 435-450.

Kripke, Saul. 1980. Naming and Necessity, revised edition. Cambridge, MA: Harvard University Press. (Originally published 1972.)

LaPorte, Joseph. 2004. Natural Kinds and Conceptual Change. Cambridge: Cambridge University Press.

Laudet, Vincent. 1997. "Evolution of the Nuclear Receptor Superfamily: Early Diversification from an Ancestral Orphan Receptor." Journal of Molecular Endocrinology 19: 207-226.

Leonelli, Sabina. 2012. "Classificatory Theory in Biology.” Biological Theory 7(4): 338-345.

Loenen, Wil A. M., David T. F. Dryden, Elisabeth A. Raleigh, Geoffrey G. Wilson, and Noreen E. Murray. 2014. "Highlights of the DNA Cutters: A Short History of the Restriction Enzymes." Nucleic Acids Research 42(1): 3-19.

Longy, Françoise. 2018. "Do we need two notions of natural kind to account for the history of 'jade??" Synthese 195: 1459-1486.

Love, Alan C. 2009. "Typology Reconfigured: From the Metaphysics of Essentialism to the Epistemology of Representation." Acta Biotheoretica 57(1-2): 51-75.

Lowe, E. J. 2007. "A Problem for a Posteriori Essentialism concerning Natural Kinds." Analysis 67(4): 286-292.

Ludwig, David. 2017. "Indigenous and Scientific Kinds." British Journal for the Philosophy of Science 68(1): 187-212.

Magnus, P. D. 2012. Scientific Enquiry and Natural Kinds: From Planets to Mallards. Basingstoke: Palgrave MacMillan.

Magnus, P. D. 2014. “NK \# HPC.” Philosophical Quarterly 64(256): 471-477.

Magnus, P. D. 2018. “Taxonomy, Ontology, and Natural Kinds.” Synthese 195: 1427-1439.

Mangelsdorf, David J., Estelita S. Ong, Jacqueline A. Dyck, and Ronald M. Evans. 1990. "Nuclear

Receptor that Identifies a Novel Retinoic Acid Response Pathway." Nature 345(6272): 224 229.

Mangelsdorf, David J., Carl Thummel, Miguel Beato, Peter Herrlich, Günther Schütz, Kazuhiko 
Umesono, Bruce Blumberg, Philippe Kastner, Manuel Mark, Pierre Chambon, and Ronald M. Evans. 1995. “The Nuclear Receptor Superfamily: The Second Decade.” Cell 83: 841850.

Martial, Joseph A., Robert A. Hallewell, John D. Baxter, and Howard M. Goodman. 1979. "Human Growth Hormone: Complementary DNA Cloning and Expression.” Science 205: 602-607.

Mayr, Ernst. 1957. "Species Concepts and Definitions." In The Species Problem, ed. Ernst Mayr, 371388. Washington, D.C.: The American Association for the Advancement of Science.

McDonnell, Donald P., David J. Mangelsdorf, J. Wesley Pike, Mark R. Haussler, and Bert W. O’Malley. 1987. "Molecular Cloning of Complementary DNA Encoding the Avian Receptor for Vitamin D." Science 235: 1214-1217.

McFarland, Andrew. 2018. "Causal powers and isomeric chemical kinds." Synthese 195: 1441-1457. Mellor, D. H. 1977. "Natural Kinds." British Journal for the Philosophy of Science 28: 299-312.

Meyer, Leroy N. 1989. "Science, Reduction and Natural Kinds." Philosophy 64(250): 535-546.

Millikan, Ruth Garrett. 1999. "Historical Kinds and the 'Species Sciences'." Philosophical Studies 95: 45-65.

Mitchell, Sandra D. 2003. Biological Complexity and Integrative Pluralism. Cambridge: Cambridge University Press.

Mitchell, Sandra D. 2009. Unsimple Truths: Science, Complexity, and Policy. Chicago: University of Chicago Press.

Moore, David D. 2012. "A Conversation with Elwood Jensen.” Annual Review of Physiology 74: 1-11.

Morgan, Thomas Hunt. 1926. The Theory of the Gene. New Haven: Yale University Press.

Morgan, Thomas Hunt. 1934. Embryology and Genetics. New York: Columbia University Press.

Mumford, Stephen. 2005. "Kinds, Essences, Powers." Ratio XVIII: 420-436.

Nagel, Ernest. 1929. "Nature and Convention." Journal of Philosophy 26(7): 169-182.

Needham, Paul. 2012. "Natural Kinds Thingamajigs." International Studies in the Philosophy of Science 26(1): 97-101.

Nuclear Receptors Nomenclature Committee. 1999. "A Unified Nomenclature System for the Nuclear Receptor Superfamily.” Cell 97: 161-163.

Petkovich, Martin, Nigel J. Brand, Andrée Krust, and Pierre Chambon. 1987. "A Human Retinoic Acid Receptor Which Belongs to the Family of Nuclear Receptors.” Nature 330(6147): 444 450.

Potochnik, Angela. 2011. “A Neurathian Conception of the Unity of Science.” Erkenntnis 74: 305319.

Potochnik, Angela. 2017. Idealization and the Aims of Science. Chicago: University of Chicago Press.

Putnam, Hilary. 1970. "Is Semantics Possible?" Metaphilosophy 1(3): 187-201.

Putnam, Hilary. 1973. "Meaning and Reference." The Journal of Philosophy 70: 699-711.

Putnam, Hilary. 1975. "The Meaning of 'Meaning'." In Language, Mind, and Knowledge: Minnesota Studies in the Philosophy of Science, vol. 7, ed. K. Gunderson, 131-193. Minneapolis: University of Minnesota Press.

Quine, Willard Van Orman. 1969. “Natural Kinds.” In Ontological Relativity \& Other Essays (pp. 114 138). New York: Columbia University Press.

Rabinow, Paul. 1996. Making PCR: A Story of Biotechnology. Chicago: University of Chicago Press.

Raj, Arjun, and Alexander van Oudenaarden. 2008. "Nature, Nurture, or Chance: Stochastic Gene Expression and Its Consequences." Cell 135: 216-226.

Rawls, John. 1971. A Theory of Justice. Cambridge, MA: Harvard University Press.

Reydon, Thomas A. C. 2006. "Generalizations and Kinds in Natural Science: The Case of Species." Studies in History and Philosophy of Biological and Biomedical Sciences 37: 230-255.

Rieppel, Olivier. 2007. "Species: kinds of individuals or individuals of a kind." Cladistics 23: 373-384. 
Rieppel, Olivier. 2010. "New Essentialism in Biology.” Philosophy of Science 77: 662-673.

Ruphy, Stéphanie. 2010. "Are Stellar Kinds Natural Kinds? A Challenging Newcomer in the

Monism/Pluralism and Realism/Antirealism Debates." Philosophy of Science 77: 1109-1120.

Ruse, Michael. 1987. "Biological Species: Natural Kinds, Individuals, or What?" British Journal for the Philosophy of Science 38(2): 225-242.

Shi, Yanhong. 2007. “Orphan Nuclear Receptors in Drug Discovery.” Drug Discovery Today 12: 440_ 445.

Slater, Matthew H. 2005. "Monism on the One Hand, Pluralism on the Other." Philosophy of Science 72: 22-42.

Slater, Matthew H. 2015. "Natural Kindness." British Journal for the Philosophy of Science 66(2): 375-411.

Smith, N. Adam, Luis M. Chiappe, Julia A. Clarke, Scott V. Edwards, Sterling J. Nesbitt, Mark A. Norell, Thomas A. Stidham, Alan Turner, Marcel van Tuinen, Jakob Vinther, and Xing Xu. 2015. 'Rhetoric vs. Reality: A Commentary on 'Bird Origins Anew' by A. Feduccia." The Auk. 132(2): 467-480.

Soames, Scott. 2007. “What Are Natural Kinds?” Philosophical Topics 35(1/2): 329-342.

Stanford, P. Kyle, and Phillip Kitcher. 2000. "Refining the Causal Theory of Reference for Natural Kind Terms." Philosopbical Studies 97: 99-129.

Stedman, Edgar, and Ellen Stedman. 1950. "Cell Specificity of Histones." Nature 166(4227): 780_ 781.

Sutherland, Earl J. 1972. "Studies on the Mechanism of Hormone Action." Science 177: 401-408.

Sutherland, Earl J., and G. Alan Robinson. 1966. "Role of Cyclic-3', 5'-AMP in Responses to Catecholamines and Other Hormones." Pharmacological Reviews 18: 145-161.

Tahko, Tuomas E. 2012. "Boundaries in Reality." Ratio XXV: 405-424.

Tahko, Tuomas E. 2015. "Natural Kind Essentialism Revisited.” Mind 124(495): 795-822.

Templeton, Alan R. 1989. "The Meaning of Species and Speciation: A Genetic Perspective." In Speciation and Its Consequences, ed. Daniel Otte and John A. Endler, 3-27. Sunderland, MA: Sinauer.

Thomason, Richmond H. 1969. "Species, Determinates and Natural Kinds." Noûs 3(1): 95-101.

Tobin, Emma. 2010. "Crosscutting Natural Kinds and the Hierarchy Thesis." In The Semantics and Metaphysics of Natural Kinds, ed. Helen Beebee and Nigel Sabbarton-Leary, 179-191. New York, NY: Routledge.

Van Valen, Leigh. 1976. "Ecological Species, Multispecies, and Oaks." Taxon 25: 233-239.

Walter, Philippe, Stephen Green, Geoffrey Greene, Andrée Knust, Jean-Marc Bornert, Jean-Marc Jeltsch, Adrien Staub, Elwood V. Jenson, Geoffrey Scrace, Mike Waterfield, and Pierre Chambon. 1985. "Cloning of the Human Estrogen Receptor cDNA." Proceedings of the National Academy of the Sciences 82: 7889-7893.

Watson, James D., and Francis H. C. Crick. 1953. "Molecular Structure of Nucleic Acids." Nature 171(4356): 737-738.

Weinberger, Cary, Catherine C. Thompson, Estelita S. Ong, Roger Lebo, Donald J. Gruol, and Ronald M. Evans. 1986. "Human Steroid-Receptors and erbA Protooncogene Products: Members of a New Superfamily of Enhancer Binding-Proteins." Cold Spring Harbor Symposia on Quantitative Biology 51: 759-772.

Whewell, Willian. 1840. The Philosophy of the Inductive Sciences. London, UK: Parker.

Wikforss, Åsa Maria. 2005. "Naming Natural Kinds.” Synthese 145(1): 65-87.

Wilkerson, T. E. 1988. "Natural Kinds.” Philosophy 63(243): 29-42.

Wilkerson, T. E. 1993. "Species, Essences and the Names of Natural Kinds." The Philosophical Quarterly 43(170): 1-19.

Wilson, Mark. 1982. "Predicate Meets Property." The Philosophical Review 91(4): 549-589. 
Wilson, Robert A. 1996. "Promiscuous Realism." British Journal for the Philosophy of Science 47(2): 303316.

Wilson, Robert A. 1999. "Realism, Essence, and Kind: Resuscitating Species Essentialism?" In Species: New Interdisciplinary Essays, ed. Robert A. Wilson, 187-207. Cambridge, MA: MIT Press.

Wilson, Robert A., Matthew J. Barker, and Ingo Brigandt. 2007. "When Traditional Essentialism Fails: Biological Natural Kinds." Philosophical Topics 35: 189-215.

Wimsatt, William C. 1994. "The Ontology of Complex Systems: Levels of Organization, Perspectives, and Causal Thickets." Canadian Journal of Philosophy 24(S1): 207-274.

Wright, Susan. 1986. "Recombinant DNA Technology and Its Social Transformation, 1972-1982," Osiris 2: 303-360.

Yi, Doogab. 2008. "Cancer, Viruses, and Mass Migration: Paul Berg's Venture into Eukaryotic Biology and the Advent of Recombinant DNA Research and Technology, 1967-1980." Journal of the History of Biology 41(4): 589-636.

Zhang, Zhengdong, Paula E. Burch, Austin J. Cooney, Rainer B. Lanz, Fred A. Pereira, Jiaqian Wu, Richard A. Gibbs, George Weinstock, and David A. Wheeler. 2004. "Genomic Analysis of the Nuclear Receptor Family: New Insights Into Structure, Regulation, and Evolution From the Rat Genome." Genome Research 14: 580-590. 